\title{
Gas-crossover and Membrane-pinhole Effects in Polymer-electrolyte Fuel Cells
}

\author{
Adam Z. Weber* ${ }^{*}$ \\ Lawrence Berkeley National Laboratory, Berkeley, California 94720
}

This paper investigates the effects of gas crossover. Specifically, mathematical simulations are conducted to elucidate the fundamental changes in fuel-cell operation as permeation of the various gases through the membrane increases. Two cases are explored, with the first one examining uniform increases in the set of gas-permeation coefficients, and the second one the existence of regions of high gas crossover (i.e., membrane pinholes). For the first case, operation at $120^{\circ} \mathrm{C}$ is studied and a maximum limit for the hydrogen permeation coefficient of $1 \times 10^{-10}$ mol/bar-cm-s for a $25 \mu \mathrm{m}$ membrane is determined. For the second case, it is shown that negative current densities and temperature spikes can arise due to mixed-potential and directcombustion effects where there are large enough pinholes, thereby impacting performance and water and thermal management.

* Electrochemical Society Member

z E-mail: azweber@lbl.gov 


\section{Introduction and General Approach}

Chief among issues limiting the widespread adoption of polymer-electrolyte fuel cells (PEFCs), especially for automotive applications, are those of lifetime or durability and cost. For the former issue, there are various PEFC failure mechanisms that have been proposed and investigated at least preliminarily. One of the known causes of sudden failure is the development of a pinhole in the membrane, thereby allowing the reactant gases to chemically short the cell. For the latter issue, one of the proposed avenues is operation at $120^{\circ} \mathrm{C}$ with dry feeds. Such a system would require less precious-metal catalyst and provide overall system simplification, thereby resulting in lower cost. Of course, one requires a membrane that can conduct protons under such conditions and not allow gas permeation; finding such a membrane is a current major research endeavor. ${ }^{1}$ In this paper, gas crossover is studied for both of these situations in terms of both goals and fundamental understanding of the crossover issue.

As gas crossover increases, one expects performance to decrease. This is the same as with methanol crossover in direct-methanol fuel cells. One also anticipates the development of mixed potentials at the electrodes and a resulting decrease in the open-circuit potential. The current efficiency should also decrease with increasing crossover due to the chemical shorting it represents. Other impacts of increased crossover could include different thermal and water management aspects, hot spots and increased membrane degradation, redistribution of the reactant and inert gases, and possibly even carbon corrosion and/or fuel starvation.

The issue of gas crossover has been investigated by various research groups. On the experimental side, it is typically done by just measuring gas-permeation coefficients for a

membrane or measuring the hydrogen crossover current density in a hydrogen-pump setup. ${ }^{2-13}$ While for the most part this allows one to determine basic values, it does not provide any 
fundamental understanding of how crossover impacts performance and what happens during crossover, with few execptions. ${ }^{13}$ Furthermore, although there are certain metrics or goals for crossover values for high-temperature $\left(120^{\circ} \mathrm{C}\right)$ applications, ${ }^{1}$ there is limited study of permeation values at these conditions. ${ }^{14}$ In terms of pinholes, there is a lack of data in the literature except to note where a pinhole has caused sudden failure. What is missing is how smaller pinholes may impact performance and what could be a good signature for a pinhole. Mathematical modeling is ideally suited to examine the above issues and examine so-called "what if" scenarios.

In terms of simulation, most models either include gas crossover as a set potential loss or combine it into the contact resistance. ${ }^{15,16}$ Some models do include gas crossover in a more rigorous fashion, but with the exception of Kocha et al. ${ }^{17}$ it is only of minimal importance and not investigated deeply. Kocha et al. examine crossover and its implications with a focus mainly on the impact of nitrogen crossing over to the anode and diluting the hydrogen, an aspect which is traditionally ignored. While Kocha et al. do a good job in discussing gas crossover, they concern themselves with the values of Nafion and do not examine what happens at high crossover rates. Finally, although methanol crossover and its detrimental impact on performance have been investigated in depth using both modeling and experiment, the same cannot be said of gas crossover in hydrogen PEFCs, which is the topic of this paper.

To study gas crossover, we use our previously developed PEFC models. ${ }^{18,19}$ The simulations are conducted using a pseudo 2-D approach, where a 1-D cell-sandwich model is run at various segments along the gas channel in a coflow arrangement, as shown in Figure 1. Although coflow is used for computational simplicity, other flow designs are expected to show similar trends and values. A 32-segment discretization was used, and the results were verified to be independent of the number of segments. The 1-D sandwich is composed of gas channels (GCs), symmetric 
diffusion media (DM) or gas-diffusion layers (GDLs), anode and cathode catalyst layers (CLs), and membrane (Mem).

The governing equations are shown in Table I. In the table, all the equations are first order with the exception of temperature, which is second order. The mass balance consumption and generation terms are either given by the appropriate kinetic expressions and reaction stoichiometry by Faraday's law or given by mass-transfer expressions for liquid and water vapor to/from the membrane. If liquid water exists, local equilibrium is assumed between the liquid and water vapor in the porous layers (DM and CLs) due to the assumption of a large interfacial contact area. The membrane is treated using our hybrid approach and a fraction of expanded channels that account for transport in both liquid- and vapor-equilibrated membranes for both water and protons; and thickness change due to swelling (equations 13 and 14) is considered. The DM are treated using our cut-and-rejoin bundle-of-capillaries approach with separate hydrophobic and hydrophilic domains. The kinetic expressions are treated using an agglomerate approach and effectiveness factors. For more in-depth discussions concerning modeling approaches, equations, and parameter expressions as well appropriate historical references, the reader is referred to references ${ }^{18}$ and ${ }^{19}$ and those contained therein.

For the boundary conditions, interstitial concentrations and superficial fluxes are continuous between layers in which the phases exist; Table II summarizes the boundary conditions. In the gas channels, simultaneous mass and energy balances are used to obtain the necessary boundary conditions for gas-phase concentrations and temperature, and these are not all shown in Table II for brevity (see reference ${ }^{19}$ for the complete expressions). Additional assumptions for the model include steady-state operation, a uniform coolant temperature, negligible gravity, and a liquid water product. 
As mentioned, it is suspected that carbon corrosion could occur due to high gas crossover,

$$
\mathrm{C}+2 \mathrm{H}_{2} \mathrm{O} \rightarrow \mathrm{CO}_{2}+4 \mathrm{H}^{+}+4 \mathrm{e}^{-}
$$

For this reason, the kinetic equation for carbon oxidation reaction (COR) is added to the set of reaction expressions. The expression and values used are derived from the work of Yu et al., ${ }^{20}$ which are in the same range as those of Meyers and Darling, ${ }^{21}$ and are given in Table III; the theoretical potential is derived from thermodynamics. ${ }^{22,23}$ The electrochemical kinetic expression is

$$
i_{\mathrm{COR}}=i_{0_{\mathrm{COR}}} \exp \left(\frac{\alpha_{\mathrm{a}_{\mathrm{COR}}} F}{R T}\left(\Phi_{1}-\Phi_{2}-U_{\mathrm{COR}}^{\theta}\right)\right)
$$

It has been reported that the rate of carbon corrosion depends on the local humidity and platinum content, ${ }^{24,25}$ however without more quantitative data, these effects are ignored.

Oxygen evolution occurs under the same conditions as carbon oxidation. To account for this, a Butler-Volmer expression is used for the oxygen reduction reaction (ORR) instead of the normal Tafel one,

$$
i_{\mathrm{ORR}}=i_{0_{\mathrm{ORR}}}\left[\exp \left(\frac{\alpha_{\mathrm{a}_{\text {ORR }}} F}{R T}\left(\Phi_{1}-\Phi_{2}-U_{\mathrm{ORR}}\right)\right)-\left(\frac{c_{\mathrm{H}_{3} \mathrm{O}^{+}}}{c_{\mathrm{H}_{3} \mathrm{O}^{+}}^{\text {ref }}}\right)^{4}\left(\frac{p_{\mathrm{O}_{2}}}{p_{\mathrm{O}_{2}}^{\text {ref }}}\right) \exp \left(\frac{-\alpha_{\mathrm{coRR}} F}{R T}\left(\Phi_{1}-\Phi_{2}-U_{\mathrm{ORR}}\right)\right)\right]
$$

and the expression for the effectiveness factor and Thiele modulus remain more-or-less unchanged. In the above expression, since a Butler-Volmer expression is used, the thermodynamic potential,

$$
U_{\mathrm{ORR}}=U_{\mathrm{ORR}}^{\theta}+\frac{R T}{4 F} \ln \left[\left(\frac{p_{\mathrm{H}_{2} \mathrm{O}}^{\text {vap }}}{p_{\mathrm{H}_{2} \mathrm{O}}}\right)^{2}\left(\frac{p_{\mathrm{O}_{2}}}{p_{\mathrm{O}_{2}}^{0}}\right)\left(\frac{p_{\mathrm{H}_{2}}}{p_{\mathrm{H}_{2}}^{0}}\right)^{2}\right]
$$

and not the standard potential is required, where the superscript denotes the reference condition of 1 bar. The above expression corresponds to a (imaginary) hydrogen reference electrode at the 
local conditions and temperature and with its own extraneous phase of hydrogen at 1 bar, thus the hydrogen term will cancel. Besides the change in the equilibrium potential, the oxygen evolution reaction is taken to be zero order with respect to the water partial pressure due to a lack of data on this effect, which should be a fine assumption since the rate of oxygen evolution is small.

The above expression also accounts for the availability of the proton for oxygen reduction. It has been shown that dry feeds result in lower kinetic rates than expected. ${ }^{26-28}$ To account for this effect, the hydronium-ion concentration is included in the kinetic expression with a power dependence corresponding to its stoichiometry, and the reference conditions correspond to the value for the membrane in contact with saturated gas. The concentration is a function of the membrane water content, $\lambda$, and the hydronium ions available for reaction, $\lambda_{\mathrm{H}_{3} \mathrm{O}^{+}}$,

$$
c_{\mathrm{H}_{3} \mathrm{O}^{+}}=\lambda_{\mathrm{H}_{3} \mathrm{O}^{+}} \frac{\frac{M_{w}}{E W} \lambda+1}{\bar{V}_{m}+\lambda \bar{V}_{w}}
$$

where $E W$ is the membrane equivalent weight, $M_{w}$ is the molecular weight of water, and $\bar{V}_{i}$ is the partial molar volume of species $i$. The value of $\lambda_{\mathrm{H}_{3} \mathrm{O}^{+}}$is calculated using a chemical model for water uptake..$^{29,30}$ The use of the concentration term in the above manner agrees with data showing significant impact on performance with $\lambda$ values lower than 6 or so and with insignificant impact above that value. ${ }^{26-28}$ In addition, it also agrees with the improvement of performance when low equivalent weight ionomers are used in the catalyst layer. ${ }^{31}$

Finally, Table III also gives the independent material- and physical-property expressions. It should be noted that many of these do not impact the results in this paper since the analysis is for gas crossover and under conditions where water management is not limiting. Most of the values 
come from our previous analyses, but a few (mass-transfer portion of the Thiele modulus and the specific interfacial area for reaction) were fit to the experimental data shown in Figure 2. While Table III gives the independent properties and expressions, the dependent ones such as membrane water content, effectiveness factors, and the relatively permeabilities are not shown for brevity; these properties are calculated using our previously described and referenced submodels.

The structure of this paper is as follows. The first part examines the changing the set of gaspermeation coefficients homogeneously in the cell. This is done using the high-temperatureoperation case since it allows for a target to be set for membrane development, while also demonstrating the fundamental impacts of gas crossover. The second part of the paper investigates the impact of single or multiple membrane pinholes of varying size (i.e., heterogeneous change in the permeation coefficients). The operating conditions for this case are

those currently in use, namely, Nafion with humidified feeds at lower temperatures. Finally, some conclusions are made.

\section{Gas-crossover Effects}

Before proceeding to examine in detail the effects of the local variations, it is of interest to examine how performance is affected by changes in the gas-permeation coefficients. While this can be done for a typical Nafion system, it is of more interest to examine the high-temperature case. The reasoning is that the permeation coefficients for Nafion are well known, whereas for a novel, high-temperature membrane, there is no conclusive metric or threshold value that has been determined. 
As shown in Figure 2, decreasing humidity for a Nafion system results in significant performance decay due to ohmic and kinetic limitations. To minimize this effect, a hypothetical membrane is used that is an anhydrous conductor, although the general trends and gas-crossover effects shown are more-or-less independent of this assumption. Thus, the membrane is modeled with a constant conductivity of $0.1 \mathrm{~S} / \mathrm{cm}$ for the bulk membrane and the membrane in the CLs (before accounting for ionomer tortuousity and volume fraction). In addition, due to lack of data, the electroosmotic coefficient is set equal to zero. This means that equation 6 in Table I is replaced by Ohm's law. Furthermore, water transport through the membrane (equation 11) then becomes the same as that of any other gas species, i.e., a permeation expression is used

$$
\mathbf{N}_{i, \mathrm{M}}=-\psi_{i} \nabla p_{i}
$$

where $p_{i}$ is the partial pressure of $i$ in the membrane phase. For the permeation coefficients, constant ratios between them for the various gas species are assumed

$$
\frac{\psi_{\mathrm{O}_{2}}}{\psi_{\mathrm{H}_{2}}}=\frac{\psi_{\mathrm{N}_{2}}}{\psi_{\mathrm{H}_{2}}}=\frac{3}{4} \frac{\psi_{\mathrm{H}_{2} \mathrm{O}}}{\psi_{\mathrm{H}_{2}}}=\frac{2}{3}
$$

The above ratios are more-or-less anticipated based on molecular interactions and polymer data (e.g., Nafion), ${ }^{29}$ and later results show that reasonable changes to them do not greatly impact the general trends. Since the ratios are constant, the rest of the analysis will be presented in terms of the hydrogen permeation coefficient since it is the largest in the system. Besides the above changes, everything remains the same for the simulations. Figure 2 shows that the hypothetical high-temperature membrane results in a performance at $120^{\circ} \mathrm{C}$ with dry inlets and a membrane thickness of $25 \mu \mathrm{m}$ that is essentially identical to the $80^{\circ} \mathrm{C}$, Nafion 112 , humidified one.

Figure 3 displays the global impact of gas crossover on polarization performance. Two scenarios were run. The first (Figure 3a) displays the polarization curve when constant feed 
stoichiometries are assumed. The performance is impacted greatest in the kinetic portion of the curve, where mixed potentials result in a low cell potential. The largest set of permeation coefficients is not shown since it is essentially off the lower end of the curve. At low current densities, stoichiometric feeds do not provide sufficient gas flow to the cell, especially under cases of high gas-crossover rates. Furthermore, as discussed in the next section, in terms of pinholes, stoichiometric feeds do not make sense since there will be a fixed flowrate available to crossover through the pinhole. For these reasons and to study gas crossover from a fundamental perspective, simulations with fixed flowrates were run as shown in Figure $3 b$. The curves exhibit some interesting behavior. As the permeation coefficients increase, negative current densities are realized at high potentials and the shape of the curve seems to plateau. Also, due to the fixed flowrates, more mass-transfer limitations show up at higher current densities. Overall, the performance under fixed flowrates and fixed utilizations are very similar except for the higher-potential range. The curves in Figure 3 at moderate values are also very similar to each other, which could be interpreted to show that overall cell polarization is not a good indicator of and can mask local performance deviations, as will be discussed in more detail in the next section.

To establish a gas crossover threshold, base conditions of a cell potential of $0.6 \mathrm{~V}$ (automotive range of interest) with fixed flowrates corresponding to hydrogen and oxygen utilizations of 0.67 and 0.25 , respectively are chosen. The gas-permeation coefficients are then altered and the current density and current efficiency (ratio of useable electrical current to total current (useable and crossover)) calculated.

Figure 4 gives the results of these simulations as a function of hydrogen-permeation coefficient for a variety of operating and property conditions. From the figure, a threshold 
hydrogen-permeation-coefficient value of around $1 \times 10^{-10} \mathrm{~mol} / \mathrm{bar}-\mathrm{cm}-\mathrm{s}$ at $120^{\circ} \mathrm{C}$ results in a current efficiency of around 100\% (i.e., no crossover effects), which decreases to around $90 \%$ at $1 \times 10^{-9} \mathrm{~mol} / \mathrm{bar}-\mathrm{cm}-\mathrm{s}$ and then sharply drops. Furthermore, at high permeability, negative current densities are again observed even at a cell potential of $0.6 \mathrm{~V}$ (although not quite at $0.5 \mathrm{~V}$ ). It should be noted that although the threshold value determined is such that there is minimal crossover, it may be that the effects of crossover in terms of membrane degradation, such as hydrogen peroxide generation, and local utilization of hydrogen will require slightly lower values, but such studies are beyond the scope of this paper due to insufficient experimental data on the specific mechanisms and reaction rates.

Figure 4 also displays simulation results for different operating and material conditions. All of the curves are similar in shape and exhibit a more-or-less similar drop off permeation value, with the outliers being those at 0.7 and $0.5 \mathrm{~V}$ due to their much different electrode polarization and initial current density. However, when one examines the current efficiency (Figure 4b), which is normalized, even these curves are only a factor of 2 or so away from the other ones. The results of Figure $4 \mathrm{~b}$ clearly demonstrate that the conclusions from this analysis are general and valid over a variety of operating conditions, such as increased pressure. This also means that the conclusions are more or less independent of flowfield geometry and structure.

The spread in the curves in Figure 4 can be directly explained by the hydrogen crossover rate, and mainly the local hydrogen partial pressure on the anode. As the hydrogen utilization goes towards unity, there is a larger impact on performance due to dilution by nitrogen crossover and the consumption of hydrogen. Thus, the curve drop off is sharper at higher utilization and the threshold permeation value lower. For example, to have $100 \%$ utilization at the end of the cell at $0.6 \mathrm{~V}$, the permeation-coefficient limit at a hydrogen utilization of 0.67 is half the value of 
that at a 0.5 utilization. With a more dilute hydrogen feed (increased humidity or decreased pressure), the initial amount of crossover is less and this causes the cell to behave slightly better and have a slightly later and shallower drop off.

The effect of oxygen is much smaller than that of hydrogen, especially when one sees the relatively good current efficiency when the oxygen permeation coefficients are increased, the oxygen utilization is changed, and the oxygen is at a higher pressure. Of course, the overall current density is more sensitive to changes on the cathode side than the anode side due to the mass-transfer limitations on the cathode side, especially along the channel as water is generated. Furthermore, if fuel-starvation conditions exist, then higher oxygen permeation would result in more significant catalyst-layer damage. ${ }^{21}$ Overall, $1 \times 10^{-10} \mathrm{~mol} / \mathrm{bar}-\mathrm{cm}-\mathrm{s}$ is a good threshold value for all conditions.

To put the threshold value in perspective, Table IV gives the hydrogen-permeationcoefficient values for various materials at $120^{\circ} \mathrm{C}$. From the table, it can be seen that the threshold value obtained from Figure 4 is greater than traditional membrane materials, but is slightly less than stagnant water and is much, much lower than stagnant air. Both of these latter cases ignore any convective movement of the liquid or gas phase, which could enhance or diminish the overall gas crossover. Furthermore, tortuosity and porosity effects are ignored, which would lower the effective permeation-coefficient value and come into play in such systems as liquid-filled pores or certain block-copolymer and reinforced systems. While small pores could work for a liquid system (the coefficients should scale linearly with volume fraction for straight channels), any air-filled pores would have to be very small and tortuous. The fact that the permeation coefficient for stagnant air is so high is one reason why pinholes are a problem, as investigated in detail later. Finally, one should note that the values reported in this 
article assume a $25 \mu \mathrm{m}$ membrane, and the effect of the permeation coefficient should scale linearly with thickness; therefore, a $12 \mu \mathrm{m}$ membrane needs to be half as permeable for the same gas-crossover flux.

To analyze the conclusions drawn from Figure 4 about the larger impact of hydrogen, and to explain the existence of negative current densities at high permeation coefficients, Figure 5 displays the crossover reaction rates, reported in terms of a partial current density. As the gaspermeation coefficients increase, there is a significant increase in the amount of crossover reaction of hydrogen at the cathode, and to smaller extent, oxygen at the anode. In fact, the reaction rate of hydrogen oxidation at the cathode is several times that of the cell electrochemical reaction, and the increase in this rate is directly associated with the decrease in the overall cell current density. Thus, the negative current densities observed in Figure $4 \mathrm{a}$ and Figure $3 \mathrm{~b}$ are due to a reversal of the potential gradient caused by the mixed-potential effect of more hydrogen being oxidized at the cathode rather than the anode. Hence, they are not indicative of carbon corrosion, which is clearly shown in Figure 7 later and in the smooth change of the catalyst-layer ionic- and electronic-potential profiles as a function of permeation coefficient (not shown). From a physical perspective, the reaction rate is dictated by the overpotential and concentration of reactants (see equation 17). Because the overpotential for the hydrogen-oxidation reaction is greater at the cathode than the anode, there is more driving force for reaction. However, this rate is typically limited by the hydrogen concentration, which is not the case as the permeation coefficient increases. The crossover point in Figure 5 corresponds to a current efficiency of 50 $\%$, where half of the hydrogen is being used for generation of useable electrons, and the other half is not. 
As a final investigation into gas crossover, it is worthwhile to examine the along-the-channel profiles at a relatively high set of gas-permeation coefficients (hydrogen value of $6 \times 10^{-8} \mathrm{~mol} / \mathrm{s}-$ bar-cm), as shown in Figure 6. Perhaps the most interesting profile is that of the current density in Figure 6a. While one would expect a small decrease in the current density due to reactant consumption for a case without crossover, the curve in Figure 6a displays a maximum with negative current densities at both the inlet and outlet regions. This shape can be explained by looking at Figure $6 \mathrm{~b}$ and $\mathrm{d}$. At the inlet region there is a significant crossover flux of hydrogen, resulting in the mixed-potential effect and negative current density described above. As one moves along the channel, the hydrogen is consumed, resulting in lower crossover and oxidation at the cathode; the net result is a positive increase in the current density. However, the hydrogen begins to be consumed to the point where there is not enough to react at the anode catalyst layer due to hydrogen consumption and dilution by crossover nitrogen, resulting in a decrease in the current density. Finally, the hydrogen is consumed and fuel-starvation condition exist, thereby resulting in carbon corrosion which is indicated by the significant change in the membrane potential (Figure 6b), which allows for the necessary overpotentials to generate oxygen and oxidize carbon at the cathode catalyst layer and reduce oxygen at the anode catalyst layer. Note that only at the outlet region and not the inlet region are the overpotentials sufficient to sustain carbon-corrosion phenomena.

Figure 6c shows the average 1-D sandwich temperature profile. As one moves down the channel, the temperature decreases (even though the current density is increasing) due to the lower amount of gas-crossover and its associated direct combustion heat release, as is implied from Figure 5. This is a somewhat different temperature profile albeit with much larger 
temperatures than a cell without crossover, which typically exhibits a small temperature increase at the inlet and then a more-or-less linear decrease.

As discussed above, Figure $6 \mathrm{~d}$ is very different than the case without crossover due to the impact of running out of hydrogen at the outlet as well as the significant increase in water and nitrogen concentrations. In fact, the accumulation of nitrogen can be a concern, especially with dead-ended cells or those that recycle the anode stream since the nitrogen becomes the majority species in the gas stream. Unlike the above profiles, those in Figure 6e for the cathode gas channel are almost the same as those for the case without crossover, with a slightly larger decrease in oxygen concentration due to the oxygen crossover, although this is mitigated to a certain extent by the water and nitrogen crossover. Overall, high gas permeation can result in negative current densities due to mixed potentials and fuel starvation and carbon corrosion, increased temperatures, hydrogen dilution, very heterogeneous reactant, potential, and currentdensity profiles, and poor performance and efficiency.

\section{Membrane-pinhole Effects}

The above analysis is focused on how the uniform changing of the gas-permeation coefficients affects performance. It provides the necessary background for the studies in this section, where the impact of a heterogeneous value is examined, namely, a pinhole in the membrane. Unlike the majority of the analysis above, the operating conditions for studying a pinhole are those of constant hydrogen and oxygen utilization of 83 and $50 \%$, respectively, Nafion 112 membrane, operating temperature of $65^{\circ} \mathrm{C}$, and fully humidified feeds. These changes are consistent with typical operating conditions of existing systems where pinholes may exist. 
In terms of simulating a pinhole, one or multiple segments are chosen in the along-thechannel discretization (see Figure 1) to contain a pinhole. The size of the pinhole is related to the active area of the cell using a volume fraction for the pinhole, $\varepsilon_{\text {hole. }}$ This value is then used to calculate a volume fraction of the membrane, $1-\varepsilon_{\text {hole }}$, which is used in a Bruggeman expression to alter the transport properties of the membrane, namely, water-transport and electroosmotic coefficients and ionic conductivity. For the gas crossover through the pinhole, the StefanMaxwell gas-phase-transport equations (see equation 8) are extended into the membrane domain with effective coefficients that depend linearly on $\varepsilon_{\text {hole }}$ (unity tortuousity is used since the pinhole is assumed to be a straight pore). The pinhole is assumed to be filled with gas and never with liquid.

To analyze the impact of a pinhole on the overall cell performance, Figure 7 shows polarization curves for the base case without a pinhole and one with a pinhole that has an area of $0.05 \%$ that of the active area. The impact of the pinhole is most apparent at high potentials due to the fact that the mixed potential and hydrogen crossover is more significant under these conditions, as discussed above. This is also expected due to the gas-permeation coefficients that arise in stagnant air (see Table IV), even though the volume fraction of such air is small. Negative current densities for the cell are not realized due both to the small size of the pinhole and the constant utilization, not flowrate, feed conditions. The impact of these conditions is similar to that seen experimentally. ${ }^{34}$

Figure 7 shows that even a small pinhole can have an impact on the overall performance. One may wonder what is happening on the local scale. Figure 8 shows both the current-density and maximum-temperature distributions along the channel at $0.6 \mathrm{~V}$. In agreement with Figure 7 , the overall performance is affected only slightly, which is seen in the small deviation post 
pinhole which is a result of extra reactant consumption and temperature deviation at the pinhole. Before the pinhole, the performance is essentially unaffected, which one may expect due to the coflow of the gases. At the pinhole, there is a large change in both the current density and especially the maximum temperature (the temperature in the gas channels is only minorly affected). This means that there is a larger temperature gradient across the GDL, which then impacts water management by a more significant heat-pipe effect that lowers the oxygen concentration at the catalyst layer. ${ }^{19}$ Therefore, the current density is much smaller than expected due both to the gas crossover and the impact of the temperature spike on water management. The magnitude of the temperature spike is probably sufficient that the use of a pseudo 2-D model may break down since in-plane temperature gradients cannot be ignored.

Figure 7 and Figure 8 focus on having a single pinhole of a given size in the middle of the cell. One may wonder what happens with multiple pinholes, larger pinholes, or a pinhole at a different location. To examine these effects, various simulations are run at $0.6 \mathrm{~V}$ and the results reported in Table V. From the table, it is apparent that for most pinhole formations, the overall impact on cell performance and current efficiency is relatively modest. This is especially true when one examines the significant local variations in terms of maximum temperature and minimum current density at the pinhole due to gas crossover. Thus, depending on overall performance is not necessarily a good signature for pinholes. Instead, one should look at such factors as temperature and current-density deviations along the cell or even the cathode-outlet hydrogen concentration. Furthermore, this should also be done with the anode pressurized more than the cathode due to the more sensitive impact of hydrogen crossover (see Figure 5), and the fact that pressure-driven flow is much more significant through the pinhole than in the cases examined in the previous section. Conversely, pressurizing the cathode relative to the anode will 
decrease the impact of the pinhole and hydrogen crossover, although the extra oxygen on the anode may generate more peroxide. ${ }^{35}$ The peroxide generation due to crossover could also be a pinhole signature and may be why pinholes accelerate membrane degradation.

Several conclusions and trends can be reached from Table V. First, the larger the pinhole the more significant the crossover and the lower the performance. Although this is not surprising, the results demonstrate that this is not a linearly increasing function, and, in fact, once a threshold value around $0.2 \%$ relative area is reached, the performance begins to decrease rapidly. The second trend is that pinhole location can be important, with pinholes nearer the inlet being more significant. Again, this is not surprising since coflow is simulated, and so the pinhole effects are felt more downstream than upstream (see Figure 8). Furthermore, the temperature spike at the inlet can cause a larger inlet area that is not fully humidified, thereby detrimentally impacting performance even more.

A third conclusion is that multiple pinholes can affect performance in a similar fashion as to having a single, yet larger, pinhole. Doing this comparison shows the interesting effect that a single, larger pinhole causes worse performance and larger local deviations than the case of a couple of pinholes (compare cases 4 and 9). However, when the number of adjacent pinholes becomes larger, their cumulative effect is more significant than the larger pinhole (compare cases 6 and 11). Finally, although not shown, this trend again reverses in that a single pinhole of relative area $0.4 \%$ shows much worse performance than that of case 15 (in fact, it could not be simulated accurately due to convergence problems related to fuel starvation and problems with having fixed utilizations at very low current densities). From the table, one can also see that with the larger pinholes or multiple pinholes, negative current densities can be observed, which are again due to mixed-potential effects as explained in the preceding section. A final conclusion 
from the simulations is that pinholes next to each other can act synergistically to lower performance. Comparing cases 17 and 18 with 11 demonstrates that the closer the pinholes are next to each other, the more significant the impact on performance and temperature. There seems to be a minimum distance that is required for the performance to decrease more than just do to the cumulative effects of the two pinholes. This distance is tied to the second pinhole feeling the disruptions in the temperature and gas composition of the first pinhole.

Finally, it is of interest to examine the maximum-temperature and current-density distributions for the case of multiple pinholes. Figure 9 displays the profiles for case 15 in Table $\mathrm{V}$, that of 8 pinholes each of $0.05 \%$ relative area. What is interesting in this case is that the maximum maximum-temperature spike is actually of more-or-less the same value as that of Figure 7, where a single pinhole of relative area $0.08 \%$ is examined. This is in contrast to the trend in Table $\mathrm{V}$ where more pinholes equaled a higher maximum temperature. The reason is twofold. First, the temperature increase and related crossover flux is being spread over a greater area and becoming more uniform along the pinhole segments. This is similar to having a larger and uniform set of gas-permeation coefficients, and thus the crossover in the latter segments is lower due to the decreased hydrogen concentration reaching the membrane at these locations. Second, the current density in the pinholes is going towards lower values and even becoming negative. This lowers the overall cell current density as well as affects the local heating and crossover. The impact on the overall current density can be seen in that Figure 9 shows a deviation from the no-pinhole case before the first pinhole due to the lower amount of feed gases and the use of fixed feed utilizations. 


\section{Conclusions}

In this paper we have examined the effect of gas crossover through the membrane. Two specific situations were investigated. The first was a $25 \mu \mathrm{m}$ membrane operated at $120^{\circ} \mathrm{C}$ with dry inlets and a conductivity of $0.1 \mathrm{~S} / \mathrm{cm}$. From this study, a value for the hydrogen permeation coefficient of $1 \times 10^{-10} \mathrm{~mol} / \mathrm{bar}-\mathrm{cm}-\mathrm{s}$ is the threshold at which gas crossover begins to affect cell performance. At higher values, the cell performance and current efficiency greatly decrease, and current reversal can occur due to the development of mixed potentials at the anode and cathode catalyst layers. High gas crossover also results in substantial hydrogen dilution by nitrogen and can lead to fuel starvation at the end of the cell and subsequent carbon corrosion. The second investigated case was that of having pinholes in the membrane. It was shown that similar to the first case, negative current densities can occur as well as temperature spikes. This local heterogeneity only has an apparent effect on the overall performance with a relative pinhole area greater than around $0.1 \%$ of the active area or if there are multiple pinholes which can act synergistically as a larger one. Both studies demonstrated that hydrogen crossover is more detrimental to cell operation than oxygen crossover, due both to the facile kinetics of hydrogen oxidation and the fact that most fuel gases are pure hydrogen. Overall, this analysis sheds some light on the fundamental impact of gas crossover in fuel-cell systems.

\section{Acknowledgements}

The author would like to thank John Newman for many helpful discussions. This work was supported by industrial sponsors and the Assistant Secretary for Energy Efficiency and Renewable Energy, Office of Hydrogen, Fuel Cell, and Infrastructure Technologies, of the U. S. Department of Energy under contract number DE-AC02-05CH11231. 


\section{List of Symbols}

\section{Roman}

$a_{1,2}^{\mathrm{o}} \quad$ interfacial area between the electronically conducting and membrane phases, $1 / \mathrm{cm}$

$\hat{C}_{p_{g}}$ heat capacity of phase $g, \mathrm{~J} / \mathrm{gK}$

$c_{i, k} \quad$ interstitial concentration of species $i$ in phase $k, \mathrm{~mol} / \mathrm{cm}^{3}$

$c_{T} \quad$ total solution concentration or molar density, $\mathrm{mol} / \mathrm{cm}^{3}$

$D_{i, j} \quad$ diffusion coefficient of $i$ in $j, \mathrm{~cm}^{2} / \mathrm{s}$

$D_{\mathrm{K}, i} \quad$ Knudsen diffusion coefficient of species $i, \mathrm{~cm}^{2} / \mathrm{s}$

$E \quad$ effectiveness factor

$E W$ equivalent weight, $\mathrm{g} / \mathrm{mol}$

$f_{\mathrm{r}, k} \quad$ fraction of the PSD made up of distribution $k$

$f_{\mathrm{ec}} \quad$ fraction of expanded pores in the membrane

F Faraday's constant, 96487 C/equiv

$h$ heat-transfer coefficient to coolant stream, W/cm ${ }^{2} \mathrm{~K}$

$H_{k} \quad$ molar enthalpy of phase $k, \mathrm{~J} / \mathrm{mol}$

$\Delta H \quad$ enthalpy change of reaction, $\mathrm{J} / \mathrm{mol}$

$\Delta H_{\text {vap }}$ heat of vaporization of water, $\mathrm{J} / \mathrm{mol}$

$\mathbf{i}_{g} \quad$ superficial current density through phase $g, \mathrm{~A} / \mathrm{cm}^{2}$

$i_{0_{h}} \quad$ exchange current density for reaction $h, \mathrm{~A} / \mathrm{cm}^{2}$

$i_{h} \quad$ transfer current for reaction $h, \mathrm{~A} / \mathrm{cm}^{3}$

I magnitude of the total current density, $\mathrm{A} / \mathrm{cm}^{2}$ 
$j_{i}^{k, p} \quad$ molar rate of transfer of species $i$ between phases $k$ and $p$ per unit volume, $\mathrm{mol} / \mathrm{cm}^{3} \cdot \mathrm{s}$

$k^{\text {eff }} \quad$ effective thermal conductivity, W/cm-K

$k_{r, h} \quad$ relative permeability of pore type $h, \mathrm{~cm}^{2}$

$k_{\text {sat }} \quad$ saturated or absolute permeability, $\mathrm{cm}^{2}$

$l \quad$ membrane thickness, $\mathrm{cm}$

$M_{i} \quad$ molecular weight of species $i, \mathrm{~g} / \mathrm{mol}$

$n_{h} \quad$ number of electrons transferred in reaction $h$

$\mathbf{N}_{i} \quad$ superficial flux density of species $i, \mathrm{~mol} / \mathrm{cm}^{2} \mathrm{~s}$

$p_{k} \quad$ total pressure of phase $k$, bar

$p_{i} \quad$ partial pressure of species $i$, bar

$p_{\mathrm{w}}^{\mathrm{vap}} \quad$ vapor pressure of water, bar

$R \quad$ universal gas constant, $8.3143 \mathrm{~J} / \mathrm{mol} \mathrm{K}$

$R_{\Omega} \quad$ total constant ohmic resistance, $\Omega \mathrm{cm}^{2}$

$s_{k} \quad$ characteristic spread of distribution $k$

$\Delta S_{h} \quad$ entropy change of reaction $h, \mathrm{~J} / \mathrm{mol}-\mathrm{K}$

$T \quad$ absolute temperature, $\mathrm{K}$

$T_{\text {ref }} \quad$ reference temperature, $303.15 \mathrm{~K}$

$U^{\theta} \quad$ theoretical cell potential, $\mathrm{V}$

$U_{H} \quad$ enthalpy potential, $\mathrm{V}$

$\mathbf{v}_{i} \quad$ superficial velocity of species $i, \mathrm{~cm} / \mathrm{s}$

$\bar{V}_{i} \quad$ (partial) molar volume of species $i, \mathrm{~cm}^{3} / \mathrm{mol}$ 
$y_{i} \quad$ gas-phase mole fraction of species $i$

z through-plane direction, $\mathrm{cm}$

\section{Greek}

$\alpha \quad$ transport coefficient in the membrane, $\mathrm{mol}^{2} / \mathrm{J} \cdot \mathrm{cm} \cdot \mathrm{s}$

$\alpha_{\mathrm{a}} \quad$ anodic transfer coefficient

$\alpha_{c} \quad$ cathodic transfer coefficient

$\gamma \quad$ surface tension, $\mathrm{N} / \mathrm{cm}$

$\varepsilon_{k} \quad$ volume fraction of phase $k$

$\varepsilon_{\text {o }} \quad$ bulk porosity

$\zeta \quad$ dimensionless membrane thickness

$\xi \quad$ electroosmotic coefficient

$\eta_{h} \quad$ overpotential of reaction $h, \mathrm{~V}$

$\theta_{h} \quad$ contact angle of pore type $h$, degrees

$\kappa \quad$ ionic conductivity of the membrane, $\mathrm{S} / \mathrm{cm}$

$\lambda \quad$ moles of water per mole of sulfonic acid sites

$\hat{\lambda} \quad$ average membrane water content

$\lambda_{\mathrm{H}_{3} \mathrm{O}^{+}}$moles of hydronium ions per mole of sulfonic acid sites

$\lambda_{i} \quad$ feed stoichiometry of reactant gas species $i$

$\mu \quad$ viscosity, $\mathrm{Pa}-\mathrm{s}$

$\mu_{i} \quad$ (electro)chemical potential of species $i, \mathrm{~J} / \mathrm{mol}$ 
$\mu_{i}^{\alpha} \quad$ electrochemical potential of species $i$ in phase $\alpha, \mathrm{J} / \mathrm{mol}$

$\Pi_{h} \quad$ Peltier coefficient for charge-transfer reaction $h, \mathrm{~V}$

$\rho_{g} \quad$ density of phase $g, \mathrm{~g} / \mathrm{cm}^{3}$

$\sigma \quad$ conductivity in the electronically conducting phase, $\mathrm{S} / \mathrm{cm}$

$\phi_{\mathrm{mt}} \quad$ mass-transfer portion of the Thiele modulus, $\mathrm{bar}^{\mathrm{c}} \mathrm{cm}^{3} \cdot \mathrm{s} / \mathrm{mol}$

$\Phi_{k} \quad=$ potential in phase $k, \mathrm{~V}$

$\psi_{i} \quad=$ permeation coefficient of species $i, \mathrm{~mol} / \mathrm{bar} \cdot \mathrm{cm} \cdot \mathrm{s}$

\section{Subscripts/Superscripts}

1 electronically conducting phase

2 ionically conducting phase

a anode

c cathode

cool coolant stream

eff effective value corrected for porosity and tortuosity

G gas phase

in fuel-cell inlet conditions

L liquid phase

M membrane phase

$\mathrm{mL}$ liquid-equilibrated membrane

$\mathrm{mV}$ vapor-equilibrated membrane

ref parameter evaluated at the reference conditions

V vapor-equilibrated membrane 


\section{References}

1. Hydrogen, fuel cells \& infrastructure technologies program; multi-year research, development and demonstration plan, Tables 3.4.2 and 3.4.3., in, p. 14, U.S. Department of Energy (2007).

2. Z. Ogumi, Z. Takehara and S. Yoshizawa, J. Electrochem. Soc., 131, 769 (1984).

3. Z. Ogumi, T. Kuroe and Z. Takehara, J. Electrochem. Soc., 132, 2601 (1985).

4. T. Sakai, H. Takenaka, N. Wakabayashi, Y. Kawami and E. Torikai, J. Electrochem. Soc., 132, 1328 (1985).

5. T. Sakai, H. Takenaka and E. Torikai, J. Electrochem. Soc., 133, 88 (1986).

6. F. N. Büchi, M. Wakizoe and S. Srinivasan, J. Electrochem. Soc., 143, 927 (1996).

7. K. Broka and P. Ekdunge, J. Appl. Electrochem., 27, 117 (1997).

8. N. Yoshida, T. Ishisaki, A. Watakabe and M. Yoshitake, Electrochim. Acta, 43, 3749 (1998).

9. S. Hietala, E. Skou and F. Sundholm, Polymer, 40, 5567 (1999).

10. A. T. Haug and R. E. White, J. Electrochem. Soc., 147, 980 (2000).

11. K. D. Kreuer, J. Membr. Sci., 185, 29 (2001).

12. P. Gode, G. Lindbergh and G. Sundholm, J. Electronanal. Chem., 518, 115 (2002).

13. M. Inaba, T. Kinumoto, M. Kiriake, R. Umebayashi, A. Tasaka and Z. Ogumi, Electrochim. Acta, 51, 5746 (2006).

14. X. Cheng, J. L. Zhang, Y. H. Tang, C. J. Song, J. Shen, D. T. Song and J. J. Zhang, J. Power Sources, 167, 25 (2007).

15. A. Z. Weber and J. Newman, Chemical Reviews, 104, 4679 (2004).

16. A. Z. Weber and J. Newman, in Advances in Fuel Cells, Vol. 1, T. S. Zhao, K.-D. Kreuer and T. V. Nguyen Editors, Elsevier, Amsterdam (2007).

17. S. S. Kocha, J. D. L. Yang and J. S. Yi, AIChE J., 52, 1916 (2006).

18. A. Z. Weber and J. Newman, J. Electrochem. Soc., 152, A677 (2005).

19. A. Z. Weber and J. Newman, J. Electrochem. Soc., 153, A2205 (2006). 
20. P. T. Yu, W. Gu, R. Makharia, F. T. Wagner and H. A. Gasteiger, ECS Transactions, 3 (1), 797 (2006).

21. J. P. Meyers and R. M. Darling, J. Electrochem. Soc., 153, A1432 (2006).

22. K. Kinoshita, Carbon. Electrochemical and Physiochemical Properties, John Wiley and Sons, New York (1988).

23. CRC Handbook of Chemistry and Physics, CRC Press, Boca Raton, FL (1979).

24. L. M. Roen, C. H. Paik and T. D. Jarvi, Electrochemical and Solid State Letters, 7, A19 (2004).

25. D. A. Stevens, M. T. Hicks, G. M. Haugen and J. R. Dahn, J. Electrochem. Soc., 152, A2309 (2005).

26. H. Xu, H. R. Kunz and J. M. Fenton, Electrochim. Acta, 52, 3525 (2007).

27. H. Xu, Y. Song, H. R. Kunz and J. M. Fenton, J. Electrochem. Soc., 152, A1828 (2005).

28. K. C. Neyerlin, H. A. Gasteiger, C. K. Mittelsteadt, J. Jorne and W. B. Gu, J. Electrochem. Soc., 152, A1073 (2005).

29. A. Z. Weber and J. Newman, J. Electrochem. Soc., 151, A311 (2004).

30. J. P. Meyers and J. Newman, J. Electrochem. Soc., 149, A710 (2002).

31. H. Xu, H. R. Kunz, L. J. Bonville and J. M. Fenton, J. Electrochem. Soc., 154, B271 (2007).

32. T. K. Gibbs and D. Pletcher, Electrochim. Acta, 25, 1105 (1980).

33. R. H. Perry and D. W. Green, Perry's Chemical Engineers' Handbook, McGraw-Hill, New York (1997).

34. M. Yandrasits, personal communication (August 2007).

35. V. A. Sethuraman, J. W. Weidner, A. T. Haug, S. Motupally and L. V. Protsailo, J. Electrochem. Soc., 155, B50 (2008).

36. Y. Song, J. M. Fenton, H. R. Kunz, L. J. Bonville and M. V. Williams, J. Electrochem. Soc., 152, A539 (2005). 


\section{Captions}

Figure 1. Schematic of the modeling domain where the 1-D (through-plane) sandwich model is run along the gas channel in coflow.

Figure 2. Polarization curves of Nafion 112 cell with anode and cathode feed humidities of $100 / 75 \%$ and $35 / 35 \%$ at $80^{\circ} \mathrm{C}$ and $120^{\circ} \mathrm{C}$, respectively. The points are data from reference ${ }^{36}$ and the lines are simulations. Also shown is a simulated cell (dotted line) at $120^{\circ} \mathrm{C}$ with dry inlets and a $25 \mu \mathrm{m}$ membrane with a conductivity of $0.1 \mathrm{~S} / \mathrm{cm}$ for the membrane and the membrane in the catalyst layers. The feed stoichiometry for all cases is 3 and 4 for hydrogen and oxygen, respectively and the cells are at ambient pressure.

Figure 3. Simulated polarization curves for different gas-permeation coefficients at $120^{\circ} \mathrm{C}$ using a $0.1 \mathrm{~S} / \mathrm{cm}, 25 \mu \mathrm{m}$ membrane and dry feeds. The feed flowrates are (a) stoichiometric at 2 and 4, or (b) fixed at a flowrate of stoichiometric of 2 and 4 at 1 $\mathrm{A} / \mathrm{cm}^{2}$, for hydrogen and oxygen, respectively.

Figure 4. Current density (a) and current efficiency (b) as a function of gas-permeation coefficient for various operating conditions and material properties. The base case simulation is $120^{\circ} \mathrm{C}$, dry feeds, $0.6 \mathrm{~V}$, stoichiometries of 1.5 and 4 at $1 \mathrm{~A} / \mathrm{cm}^{2}$ for hydrogen and oxygen, respectively, relative gas-permeations coefficients as given in equation 19 , and a $0.1 \mathrm{~S} / \mathrm{cm}, 25 \mu \mathrm{m}$ membrane.

Figure 5. Crossover reaction rates expressed as a current density and overall cell current density as a function of gas-permeation coefficient. The simulation is for $0.6 \mathrm{~V}, 120^{\circ} \mathrm{C}$, dry feeds, and a $0.1 \mathrm{~S} / \mathrm{cm}, 25 \mu \mathrm{m}$ membrane. 
Figure 6. Along-the-channel values (inlet on left, outlet on right) for the (a) current density, (b) anode and cathode catalyst-layer average electronic and average ionic potentials, (c) average sandwich temperature, (d) nitrogen, water, and hydrogen mole fractions in the anode gas channel, and (d) nitrogen, water, and oxygen mole fractions in the cathode gas channel. The simulation is for a hydrogen permeation coefficient of $6 \times 10^{-8} \mathrm{~mol} / \mathrm{s}-\mathrm{bar}-\mathrm{cm}, 0.6 \mathrm{~V}, 120^{\circ} \mathrm{C}$, dry feeds, and a $0.1 \mathrm{~S} / \mathrm{cm}, 25 \mu \mathrm{m}$ membrane.

Figure 7. Polarization and current-efficiency curves for the case with and without a pinhole. The pinhole is in the middle of the cell and has a size of $0.08 \%$ of the active area. The simulation conditions are Nafion $112,65^{\circ} \mathrm{C}$, saturated inlets with utilizations of 83 and $50 \%$ for hydrogen and air, respectively.

Figure 8. Along-the-channel values for the current density and maximum temperature (occurs in the cathode catalyst layer) with and without a pinhole. The conditions are the same as Figure 7 and the simulation is done at $0.6 \mathrm{~V}$.

Figure 9. Along-the-channel values for the current density and maximum temperature (occurs in the cathode catalyst layer) for the cases without a pinhole and with 8 adjacent pinholes for a total area of $0.4 \%$ of the active area at $0.6 \mathrm{~V}$ (case 15 in Table V).

Table I. Governing equations and region(s) in which they apply. The gas species are lumped together in the table and the source terms, $j$, represent generation/consumption and are given by the transfer current densities and Faraday's law or evaporation/condensation in the case of water vapor. 
Table II. Mathematical-model boundary conditions. Temperature has two (only anode is shown) and mass balances are used for the gas species, similar to that given for water.

Table III. Model parameter values.

Table IV. Hydrogen-permeation-coefficient values at $120^{\circ} \mathrm{C}$ for different materials.

Table V. Cell current density, current efficiency, minimum segment current density, and maximum segment temperature in the cathode catalyst layer as a function of pinhole number, position, and size. The simulation conditions are Nafion $112,65^{\circ} \mathrm{C}, 0.6 \mathrm{~V}$, saturated inlets with fixed utilizations of 83 and $50 \%$ for hydrogen and air, respectively. 
Table I. Governing equations and region(s) in which they apply. The gas species are lumped together in the table and the source terms, $j$, represent generation/consumption and are given by the transfer current densities and Faraday's law or evaporation/condensation in the case of water vapor.

\begin{tabular}{|c|c|c|c|}
\hline Variable & Governing Equation & Region & Label \\
\hline $\begin{array}{l}\text { Liquid pressure } \\
\text { (equilibrium) }\end{array}$ & $p_{L}=p_{G}+\frac{R T}{\bar{V}_{\mathrm{w}}} \ln \left(\frac{y_{\mathrm{w}} p_{\mathrm{G}}}{p_{\mathrm{w}, \mathrm{o}}^{\mathrm{vap}}}\right)$ & DM, CL & {$[1]$} \\
\hline Liquid flux & $\mathbf{N}_{\mathrm{w}, \mathrm{L}}=-\frac{k_{\mathrm{sat}} k_{r, \mathrm{~L}}}{\bar{V}_{\mathrm{w}} \mu_{\mathrm{w}}} \nabla p_{L}$ & $\mathrm{DM}, \mathrm{CL}$ & {$[2]$} \\
\hline $\begin{array}{l}\text { Electronic current } \\
\text { density }\end{array}$ & $\nabla \cdot \mathbf{i}_{1}+\nabla \cdot \mathbf{i}_{2}=0$ & DM, CL & {$[3]$} \\
\hline Electronic potential & $\mathbf{i}_{1}=-\sigma_{0} \varepsilon_{1}^{1.5} \nabla \Phi_{1}$ & $\mathrm{DM}, \mathrm{CL}$ & {$[4]$} \\
\hline $\begin{array}{l}\text { Ionic current } \\
\text { density }\end{array}$ & $\nabla \cdot \mathbf{i}_{2}=\sum_{h} a_{1,2}^{\mathrm{o}}(1-S) i_{h} E_{h}$ & CL, Mem & {$[5]$} \\
\hline Ionic potential & $+\left(1-f_{\mathrm{ec}}\right)\left(-\kappa_{\mathrm{V}} \nabla \Phi_{2}-\frac{\kappa_{\mathrm{V}} \xi_{\mathrm{V}}}{F} \nabla \mu_{\mathrm{w}}\right)$ & CL, Mem & {$[6]$} \\
\hline Temperature & $\begin{array}{l}\left(\hat{C}_{p, \mathrm{G}} \mathbf{N}_{\mathrm{G}}+\hat{C}_{p, \mathrm{~L}}\left(\mathbf{N}_{\mathrm{L}}+\mathbf{N}_{\mathrm{L}, \mathrm{M}}\right)\right) \nabla T- \\
k^{\mathrm{eff}} \nabla \cdot(\nabla T)=\frac{\mathbf{i}_{1} \cdot \mathbf{i}_{1}}{\sigma_{\mathrm{o}} \varepsilon_{1}^{1.5}}+\frac{\mathbf{i}_{2} \cdot \mathbf{i}_{2}}{\kappa_{\mathrm{o}} \varepsilon_{\mathrm{M}}^{1.5}}+ \\
\Delta H_{\mathrm{vap}} j_{\mathrm{w}}^{\mathrm{G}, \mathrm{L}}+\sum_{h} i_{h}\left(\eta_{h}+\Pi_{h}\right)\end{array}$ & DM, CL, Mem & [7] \\
\hline Gas species & $\begin{array}{l}\nabla y_{i}=-\frac{y_{i}}{R T}\left(\bar{V}_{i}-\frac{M_{i}}{\rho_{\mathrm{G}}}\right) \nabla p_{\mathrm{G}}+ \\
\sum_{\substack{j \neq i \\
j \neq s}} \frac{y_{i} \mathbf{N}_{j}-y_{j} \mathbf{N}_{i}}{c_{T} D_{i, j}^{\mathrm{eff}}}-\frac{\mathbf{N}_{i}}{c_{T} D_{\mathrm{K}_{i}}^{\text {eff }}}\end{array}$ & DM, CL & [8] \\
\hline
\end{tabular}




\begin{tabular}{|c|c|c|c|}
\hline Gas species flux & $\nabla \cdot \mathbf{N}_{i}=j_{i}$ & $\mathrm{DM}, \mathrm{CL}$ & [9] \\
\hline Gas pressure & $\mathbf{v}_{\mathrm{G}}=-\frac{k_{\mathrm{sat}} k_{r, \mathrm{G}}}{\mu_{\mathrm{G}}} \nabla p_{\mathrm{G}}$ & $\mathrm{DM}, \mathrm{CL}$ & [10] \\
\hline $\begin{array}{l}\text { Membrane water } \\
\text { chemical potential }\end{array}$ & $\begin{array}{r}\mathbf{N}_{\mathrm{w}, \mathrm{M}}=f_{\mathrm{ec}}\left[-\frac{\kappa_{\mathrm{L}} \xi_{\mathrm{L}}}{F} \nabla \Phi_{2}-\left(\alpha_{\mathrm{L}}+\frac{\kappa_{\mathrm{L}} \xi_{\mathrm{L}}^{2}}{F^{2}}\right) \bar{V}_{\mathrm{w}} \nabla p_{\mathrm{L}}\right] \\
+\left(1-f_{\mathrm{ec}}\right)\left[-\frac{\kappa_{\mathrm{V}} \xi_{\mathrm{V}}}{F} \nabla \Phi_{2}-\left(\alpha_{\mathrm{V}}+\frac{\kappa_{\mathrm{V}} \xi_{\mathrm{V}}^{2}}{F^{2}}\right) \nabla \mu_{\mathrm{w}}\right]\end{array}$ & CL, Mem & [11] \\
\hline $\begin{array}{l}\text { Membrane water } \\
\text { flux }\end{array}$ & $\nabla \cdot \mathbf{N}_{\mathrm{w}, \mathrm{M}}=-j_{\mathrm{w}}^{\mathrm{mL}, \mathrm{L}}-j_{\mathrm{w}}^{\mathrm{mV}, \mathrm{G}}+\frac{1}{2 F} a_{1,2}^{\mathrm{o}}(1-S) i_{\mathrm{ORR}, 1-2} E$ & CL, Mem & [12] \\
\hline $\begin{array}{l}\text { Membrane } \\
\text { thickness }\end{array}$ & $\frac{\mathrm{d} l}{\mathrm{~d} \zeta}=0$ & Mem & [13] \\
\hline $\begin{array}{l}\text { Membrane average } \\
\text { water content }\end{array}$ & $\hat{\lambda}=\frac{1}{l} \int_{0}^{z=l} \lambda(z) \mathrm{d} z=\int_{0}^{1} \lambda(\varsigma) \mathrm{d} \varsigma$ & Mem & [14] \\
\hline $\begin{array}{l}\text { Membrane gas } \\
\text { crossover }\end{array}$ & $\mathbf{N}_{i, \mathrm{M}}=-\psi_{i} \nabla y_{i}$ & Mem & {$[15]$} \\
\hline
\end{tabular}




\section{Table II}

\begin{tabular}{|c|c|c|}
\hline Variable & Boundary Condition & Boundary \\
\hline Liquid pressure & $\begin{array}{l}p_{\mathrm{L}}=p_{\mathrm{G}} \text { for } p_{\mathrm{L}} \geq p_{\mathrm{G}} \\
\frac{y_{\mathrm{w}, \mathrm{G}}}{1-y_{\mathrm{w}, \mathrm{G}}}\left(\frac{\lambda_{\mathrm{H}_{2}} I}{2 F}-\left.\mathbf{N}_{\mathrm{H}_{2}}\right|_{\mathrm{aDM}}\right)= \\
-\left.\mathbf{N}_{\mathrm{w}, \mathrm{G}}\right|_{\mathrm{aDM}}-\left.\mathbf{N}_{\mathrm{w}, \mathrm{L}}\right|_{\mathrm{aDM}} \\
\text { for } p_{\mathrm{L}}<p_{\mathrm{G}}\end{array}$ & anode GC/DM \\
\hline Liquid flux & $\begin{array}{l}p_{\mathrm{L}}=p_{\mathrm{G}} \text { for } p_{\mathrm{L}} \geq p_{\mathrm{G}} \\
\frac{y_{\mathrm{w}, \mathrm{G}}}{1-y_{\mathrm{w}, \mathrm{G}}}\left(\frac{\lambda_{\text {air }} I}{4 F}+\left.\mathbf{N}_{\mathrm{O}_{2}}\right|_{\mathrm{cDM}}\right)= \\
+\left.\mathbf{N}_{\mathrm{w}, \mathrm{G}}\right|_{\mathrm{cDM}}+\left.\mathbf{N}_{\mathrm{w}, \mathrm{L}}\right|_{\mathrm{cDM}} \\
\quad \text { for } p_{\mathrm{L}}<p_{\mathrm{G}}\end{array}$ & cathode GC/DM \\
\hline Electronic current density & $\mathbf{i}_{1}=0$ & CL/Mem \\
\hline Electronic potential & $\Phi_{1}=0$ & anode GC/DM \\
\hline Ionic current density & $\mathbf{i}_{2}=0$ & $\mathrm{DM} / \mathrm{CL}$ \\
\hline Ionic potential & $\Phi_{1}=\Phi_{\text {cell }}$ & cathode GC/DM \\
\hline Temperature & $\begin{array}{l}\text { Energy balance, e.g. anode: } \\
h\left(T-T_{\text {cool }}\right)=\left.k^{\text {eff }} \Delta T\right|_{\mathrm{aDM}} \\
+\mathbf{N}_{\mathrm{w}}^{\text {cond }} \Delta H_{\mathrm{vap}} \\
+H_{\mathrm{G}}^{\text {in }}\left(\frac{\lambda_{\mathrm{H}_{2}} I}{2 F} \frac{1}{1-y_{\mathrm{w}, \mathrm{G}}^{\text {in }}}\right)-H_{\mathrm{G}} \mathbf{N}_{\mathrm{G}} \\
-\left.H_{\mathrm{G}}\right|_{\mathrm{aDM}}\left(\left.\mathbf{N}_{\mathrm{w}, \mathrm{G}}\right|_{\mathrm{aDM}}+\left.\mathbf{N}_{\mathrm{H}_{2}}\right|_{\mathrm{aDM}}\right) \\
-H_{\mathrm{L}}\left(\mathbf{N}_{\mathrm{w}, \mathrm{L}}+\left.\mathbf{N}_{\mathrm{w}, \mathrm{L}}\right|_{\mathrm{aDM}}\right)\end{array}$ & GC/DM \\
\hline $\begin{array}{c}\text { Gas species } \\
\text { Gas species flux }\end{array}$ & $\begin{array}{l}\text { Mass balance } \\
\text { Mass balance }\end{array}$ & $\begin{array}{c}\text { anode GC/DM } \\
\text { cathode GC/DM }\end{array}$ \\
\hline Gas pressure & $p_{\mathrm{G}}=p_{\mathrm{G}}^{\text {in }}$ & $\mathrm{GC} / \mathrm{DM}$ \\
\hline Membrane water chemical potential & $\mu_{\mathrm{w}}=R T \ln \left(\frac{y_{\mathrm{w}} p_{\mathrm{G}}}{p_{\mathrm{w}, \mathrm{o}}^{\mathrm{vap}}}\right)+\bar{V}_{\mathrm{w}}\left(p_{\mathrm{L}}-p_{\mathrm{L}}^{\mathrm{ref}}\right)$ & cathode CL/DM \\
\hline Membrane water flux & $\mathbf{N}_{\mathrm{w}, \mathrm{M}}=0$ & anode CL/DM \\
\hline $\begin{array}{c}\text { Membrane thickness } \\
\text { Membrane average water content } \\
\text { Membrane gas crossover }\end{array}$ & $\begin{array}{c}l=l_{\mathrm{o}}\left(1+0.36 \frac{\hat{\lambda} \bar{V}_{\mathrm{w}}}{\bar{V}_{\mathrm{M}}}\right) \\
\hat{\lambda}=0 \\
\mathbf{N}_{i, \mathrm{M}}=\mathbf{N}_{i, \mathrm{G}}\end{array}$ & $\begin{array}{c}\text { cathode } \\
\text { CL/Mem } \\
\text { anode CL/Mem } \\
\text { CL/Mem }\end{array}$ \\
\hline
\end{tabular}


Table III. Model parameter values.

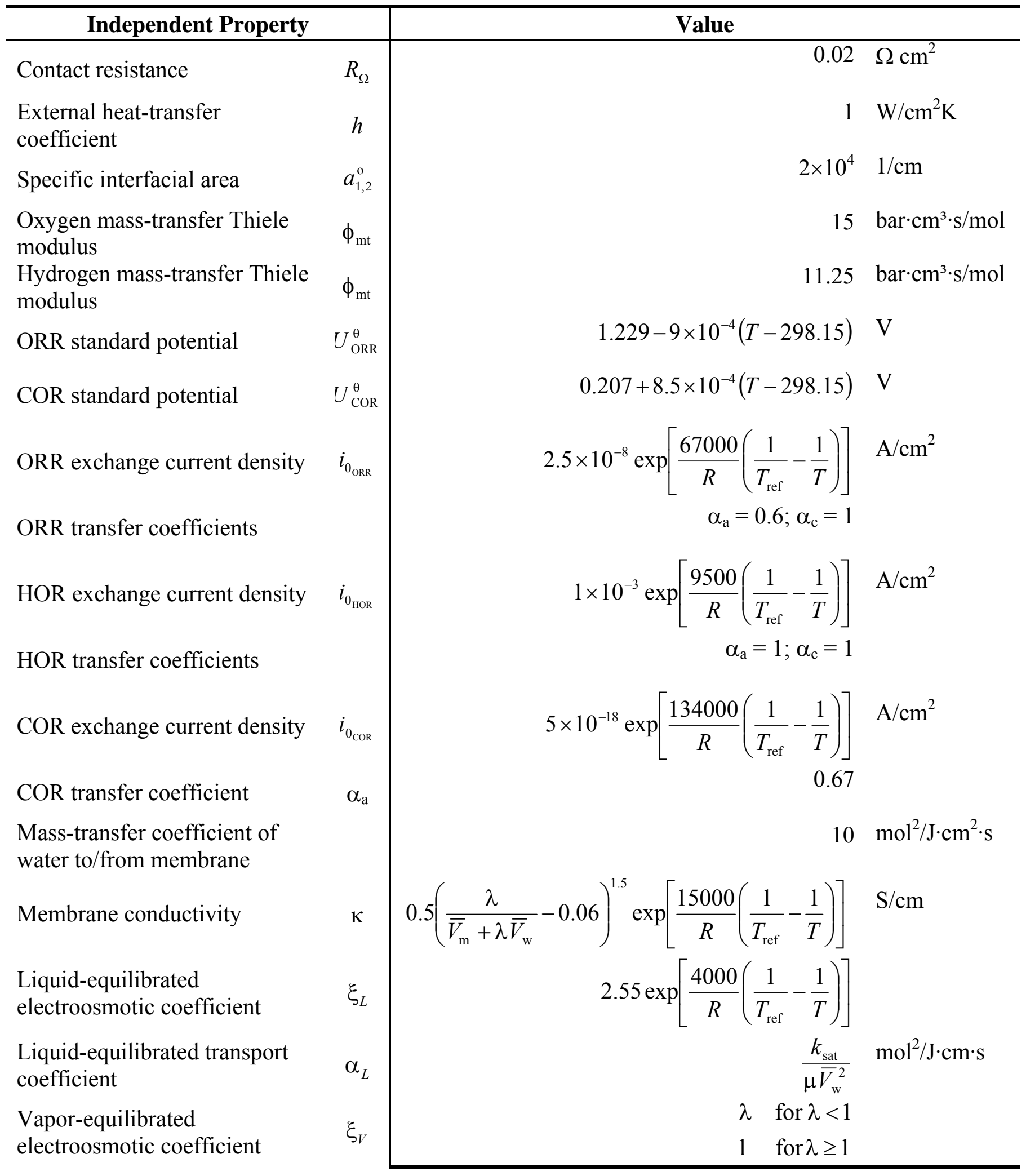


Vapor-equilibrated transport coefficient

Membrane CL volume fraction

Absolute permeability

Thickness

Thermal conductivity

Bulk porosity

Electrical conductivity

Pore-size distribution

properties

Characteristic radii

Characteristic spreads

Fraction that is distribution 1

Fraction of hydrophilic pores

Hydrophobic contact angle

Hydrophilic contact angle
$\alpha_{V}$

$$
\frac{1.8 \times 10^{-5} \lambda^{2} \bar{V}_{\mathrm{w}} \exp \left[\frac{20000}{R}\left(\frac{1}{T_{\text {ref }}}-\frac{1}{T}\right)\right]}{\left(\bar{V}_{\mathrm{m}}+\lambda \bar{V}_{\mathrm{w}}\right)^{2} R T\left(1-\frac{\lambda}{\lambda+1}\right)} \mathrm{mol}^{2} / \mathrm{J} \cdot \mathrm{cm} \cdot \mathrm{s}
$$

0.4

\section{Region}

DM Mem

$$
k_{\text {sat }}
$$

$\delta$

$k^{\text {eff }}$

$\varepsilon_{\mathrm{o}}$

$\sigma$

\begin{tabular}{|c|}
$\mathrm{CL}$ \\
\hline $1 \times 10^{-12}$
\end{tabular}

$5 \times 10^{-9}$

250

0.015

0.7

7

10

0.003

0.3

0.2

0.05

1.2

0.5

$S_{2}$

$f_{r, 1}$

$f_{\mathrm{HI}}$

$\theta_{\mathrm{HO}}$

0.5

0.3

110

$\theta_{\mathrm{HI}}$
6

0.7

0.6

1

0.95

0.2

100

80

$\begin{array}{cl}1.8 \times 10^{-14} & \mathrm{~cm}^{2} \\ 25 & \mu \mathrm{m} \\ 0.0025 & \mathrm{~W} / \mathrm{cm} \cdot \mathrm{K} \\ 0 & \\ 0 & \mathrm{~S} / \mathrm{cm}\end{array}$

$0.00125 \mu \mathrm{m}$

$\mathrm{N} / \mathrm{A} \quad \mu \mathrm{m}$

0.3

N/A

1

0

90.02 ○

N/A $\quad \circ$ 
Table IV. Hydrogen-permeation-coefficient values at $120^{\circ} \mathrm{C}$ for different materials.

\begin{tabular}{ccc}
\hline Material & $\begin{array}{c}\text { Hydrogen permeation coefficient } \\
\text { (mol/bar-cm-s) }\end{array}$ & Reference \\
\hline Teflon & $2 \times 10^{-11}$ & 3,32 \\
Nafion (dry) & $3 \times 10^{-11}$ & 29 \\
Nafion (wet) & $9 \times 10^{-11}$ & 29 \\
Stagnant liquid water & $3 \times 10^{-10}$ & 23,33 \\
Stagnant air & $3 \times 10^{-5}$ & 23,33 \\
\hline
\end{tabular}


Table V. Cell current density, current efficiency, minimum segment current density, and maximum segment temperature in the cathode catalyst layer as a function of pinhole number, position, and size. The simulation conditions are Nafion $112,65^{\circ} \mathrm{C}, 0.6 \mathrm{~V}$, saturated inlets with fixed utilizations of 83 and $50 \%$ for hydrogen and air, respectively.

\begin{tabular}{c|ccc|cccc}
\hline Case & $\begin{array}{c}\text { Size } \\
(\% \text { area) }\end{array}$ & $\begin{array}{c}\text { Pinhole } \\
\text { Number }\end{array}$ & Position $^{*}$ & $\begin{array}{c}\boldsymbol{i}_{\text {cell }} \\
\left(\mathbf{A} / \mathbf{c m}^{2}\right)\end{array}$ & $\boldsymbol{\eta}_{\boldsymbol{i}}$ & $\begin{array}{c}\boldsymbol{i}_{\text {min }} \\
\left(\mathbf{A} / \mathbf{c m}^{2}\right)\end{array}$ & $\begin{array}{c}\boldsymbol{T}_{\text {max }} \\
\left({ }^{\circ} \mathbf{C}\right)\end{array}$ \\
\hline 1 & 0 & 0 & $\mathrm{~N} / \mathrm{A}$ & 1.01 & 0.998 & 0.89 & 68.5 \\
2 & 0.05 & 1 & $\mathrm{M}$ & 0.980 & 0.970 & 0.71 & 70.0 \\
3 & 0.08 & 1 & $\mathrm{M}$ & 0.947 & 0.966 & 0.21 & 71.6 \\
4 & 0.1 & 1 & $\mathrm{M}$ & 0.917 & 0.945 & 0.27 & 72.2 \\
5 & 0.16 & 1 & $\mathrm{M}$ & 0.905 & 0.928 & 0.31 & 72.4 \\
6 & 0.2 & 1 & $\mathrm{M}$ & 0.887 & 0.913 & 0.29 & 72.5 \\
7 & 0.05 & 1 & $\mathrm{I}$ & 0.946 & 0.950 & 0.40 & 72.4 \\
8 & 0.05 & 1 & $\mathrm{O}$ & 1.00 & 0.993 & 0.84 & 68.9 \\
9 & 0.1 & 2 & $\mathrm{M}$ & 0.944 & 0.942 & 0.193 & 71.9 \\
10 & 0.15 & 3 & $\mathrm{M}$ & 0.907 & 0.913 & 0.15 & 71.8 \\
11 & 0.2 & 4 & $\mathrm{M}$ & 0.868 & 0.882 & 0.12 & 73.4 \\
12 & 0.25 & 5 & $\mathrm{M}$ & 0.816 & 0.854 & 0.01 & 72.9 \\
13 & 0.3 & 6 & $\mathrm{M}$ & 0.763 & 0.819 & -0.04 & 74.2 \\
14 & 0.35 & 7 & $\mathrm{M}$ & 0.702 & 0.783 & -0.16 & 74.9 \\
15 & 0.4 & 8 & $\mathrm{M}$ & 0.613 & 0.744 & -0.2 & 72.0 \\
16 & 0.45 & 9 & $\mathrm{M}$ & 0.326 & 0.603 & -0.96 & 71.0 \\
17 & 0.2 & 4 & $2 \mathrm{I}, 2 \mathrm{O}$ & 0.935 & 0.896 & 0.37 & 72.4 \\
18 & 0.2 & 4 & $2 \mathrm{I}, 2 \mathrm{M}$ & 0.871 & 0.884 & 0.35 & 72.5 \\
\hline
\end{tabular}

* $\mathrm{M}=$ Middle, $\mathrm{I}=$ inlet, $\mathrm{O}=$ Outlet; middle for multiple pinholes means they are adjacent in the cell middle 


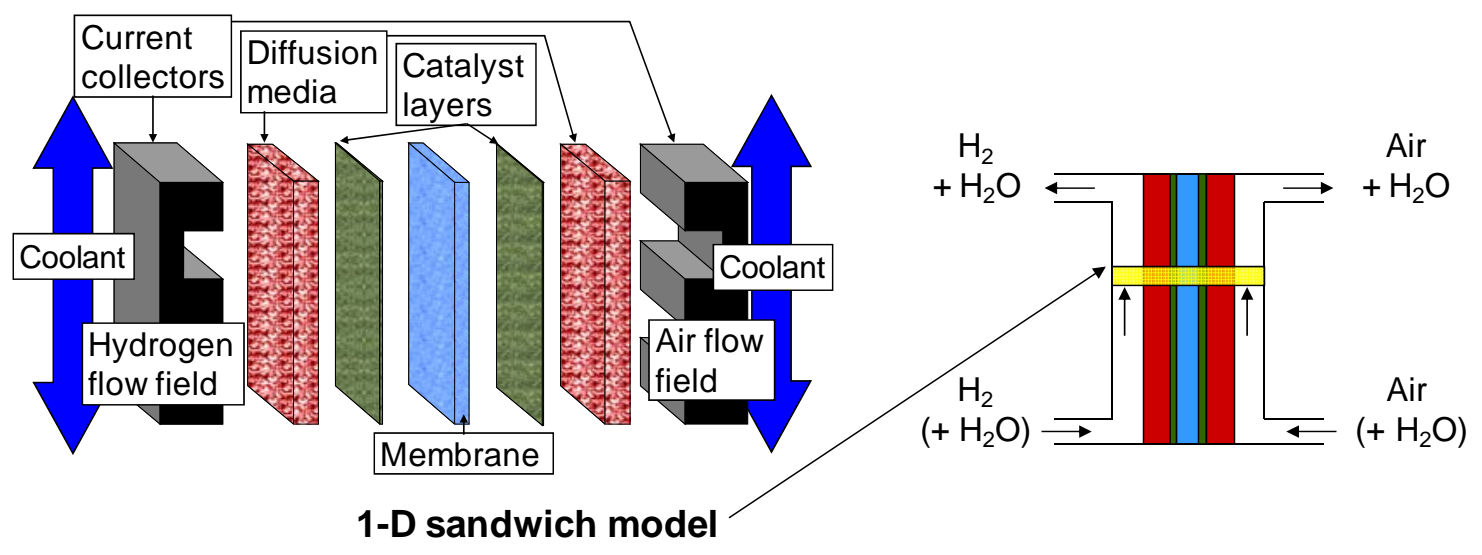

Figure 1. Schematic of the modeling domain where the 1-D (through-plane) sandwich model is run along the gas channel in coflow. 


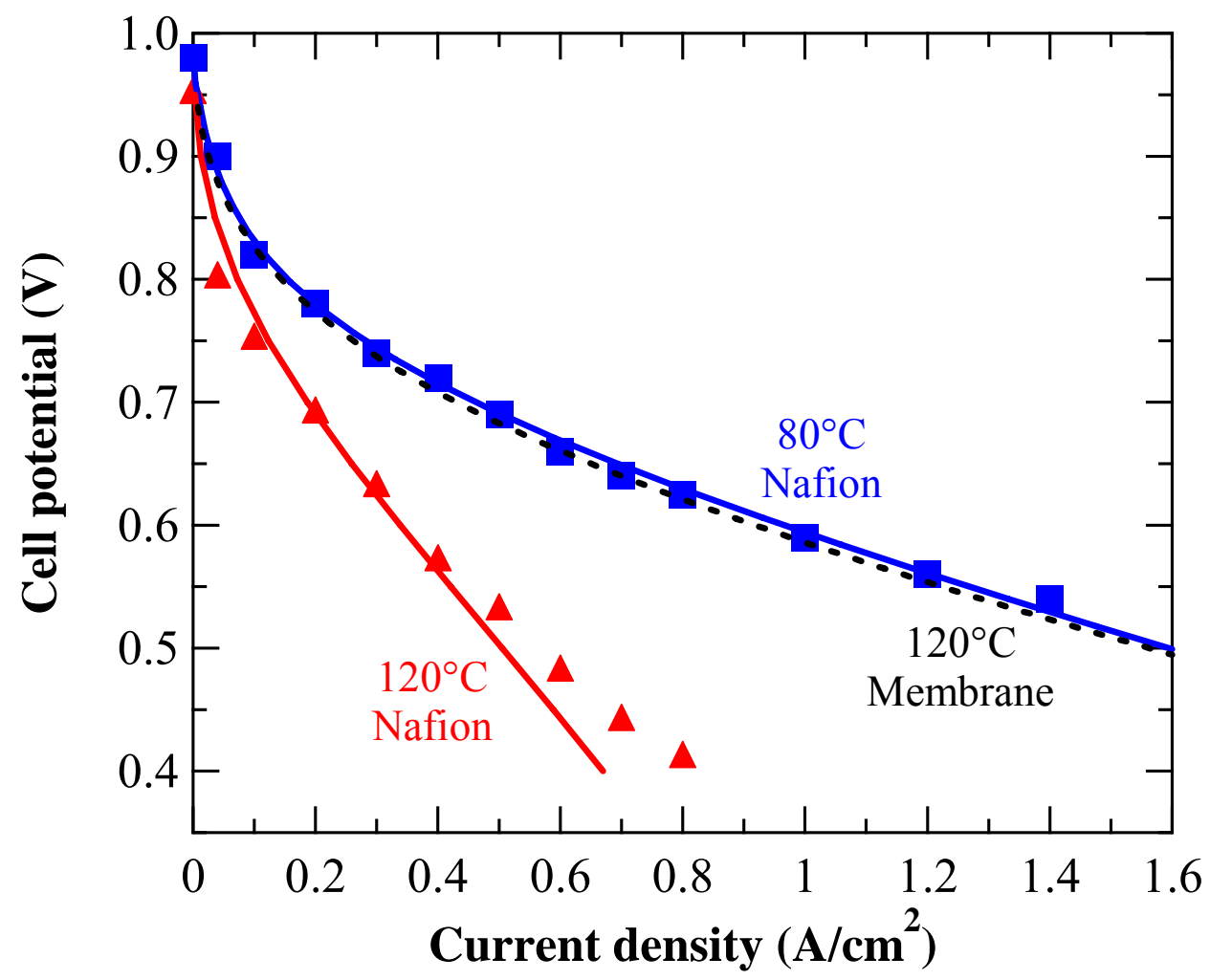

Figure 2. Polarization curves of Nafion 112 cell with anode and cathode feed humidities of $100 / 75 \%$ and $35 / 35 \%$ at $80^{\circ} \mathrm{C}$ and $120^{\circ} \mathrm{C}$, respectively. The points are data from reference ${ }^{36}$ and the lines are simulations. Also shown is a simulated cell (dotted line) at $120^{\circ} \mathrm{C}$ with dry inlets and a $25 \mu \mathrm{m}$ membrane with a conductivity of $0.1 \mathrm{~S} / \mathrm{cm}$ for the membrane and the membrane in the catalyst layers. The feed stoichiometry for all cases is 3 and 4 for hydrogen and oxygen, respectively and the cells are at ambient pressure. 


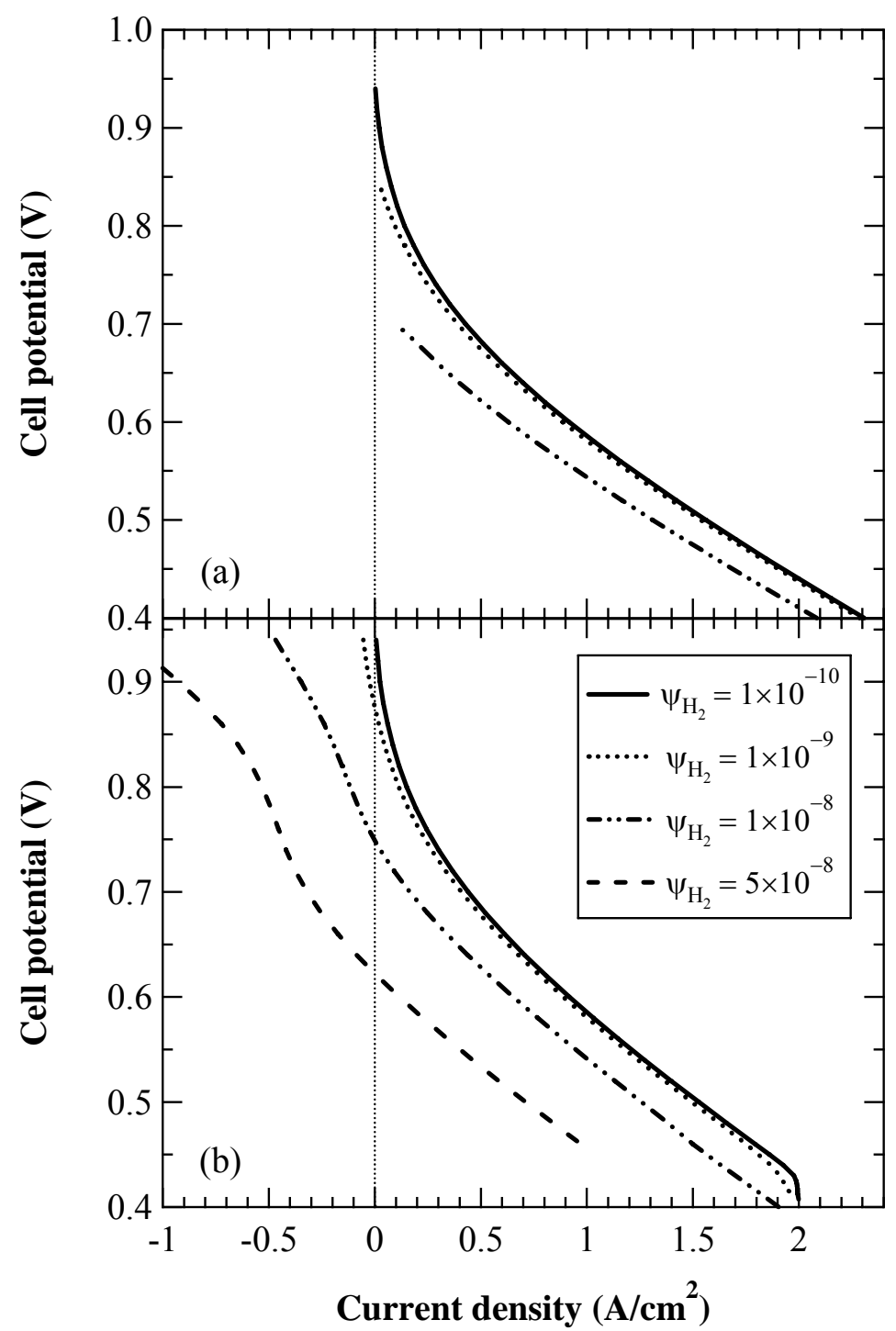

Figure 3. Simulated polarization curves for different gas-permeation coefficients at $120^{\circ} \mathrm{C}$ using a $0.1 \mathrm{~S} / \mathrm{cm}, 25 \mu \mathrm{m}$ membrane and dry feeds. The feed flowrates are (a) stoichiometric at 2 and 4 , or (b) fixed at a flowrate of stoichiometric of 2 and 4 at $1 \mathrm{~A} / \mathrm{cm}^{2}$, for hydrogen and oxygen, respectively. 


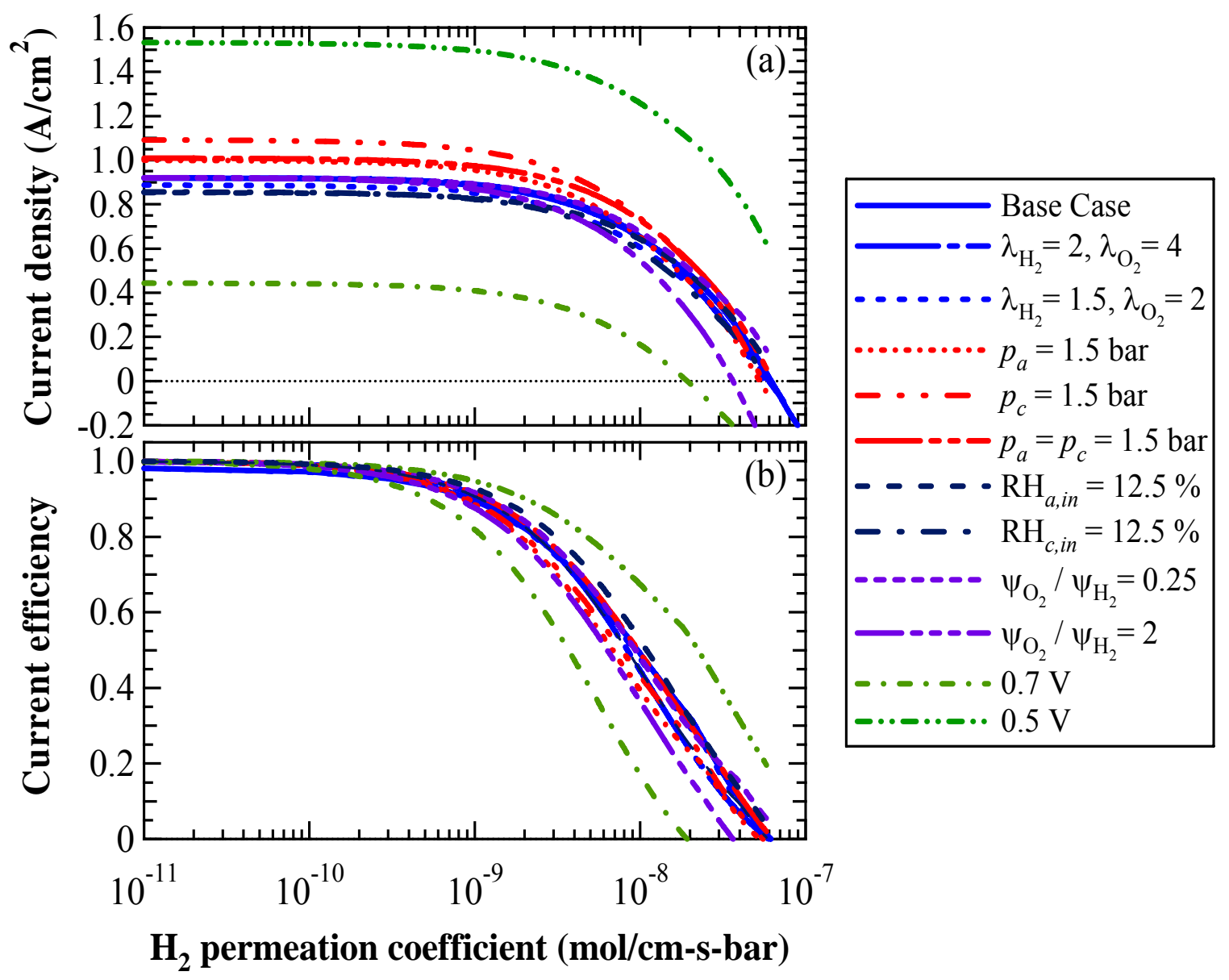

Figure 4. Current density (a) and current efficiency (b) as a function of gas-permeation coefficient for various operating conditions and material properties. The base case simulation is $120^{\circ} \mathrm{C}$, dry feeds, $0.6 \mathrm{~V}$, stoichiometries of 1.5 and 4 at $1 \mathrm{~A} / \mathrm{cm}^{2}$ for hydrogen and oxygen, respectively, relative gas-permeations coefficients as given in equation 19 , and a $0.1 \mathrm{~S} / \mathrm{cm}, 25$ $\mu \mathrm{m}$ membrane. 


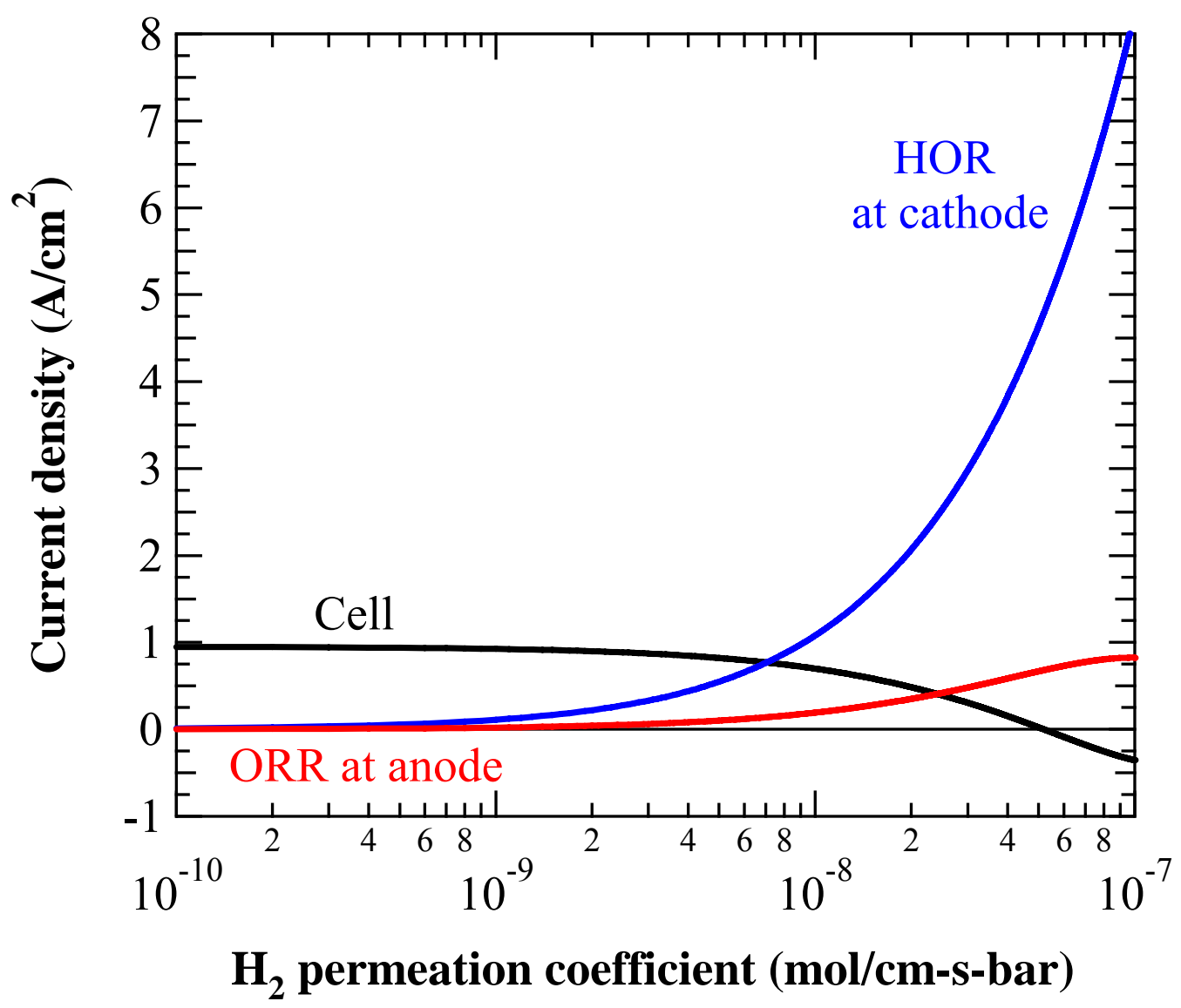

Figure 5. Crossover reaction rates expressed as a current density and overall cell current density as a function of gas-permeation coefficient. The simulation is for $0.6 \mathrm{~V}, 120^{\circ} \mathrm{C}$, dry feeds, and a $0.1 \mathrm{~S} / \mathrm{cm}, 25 \mathrm{~m}$ membrane. 

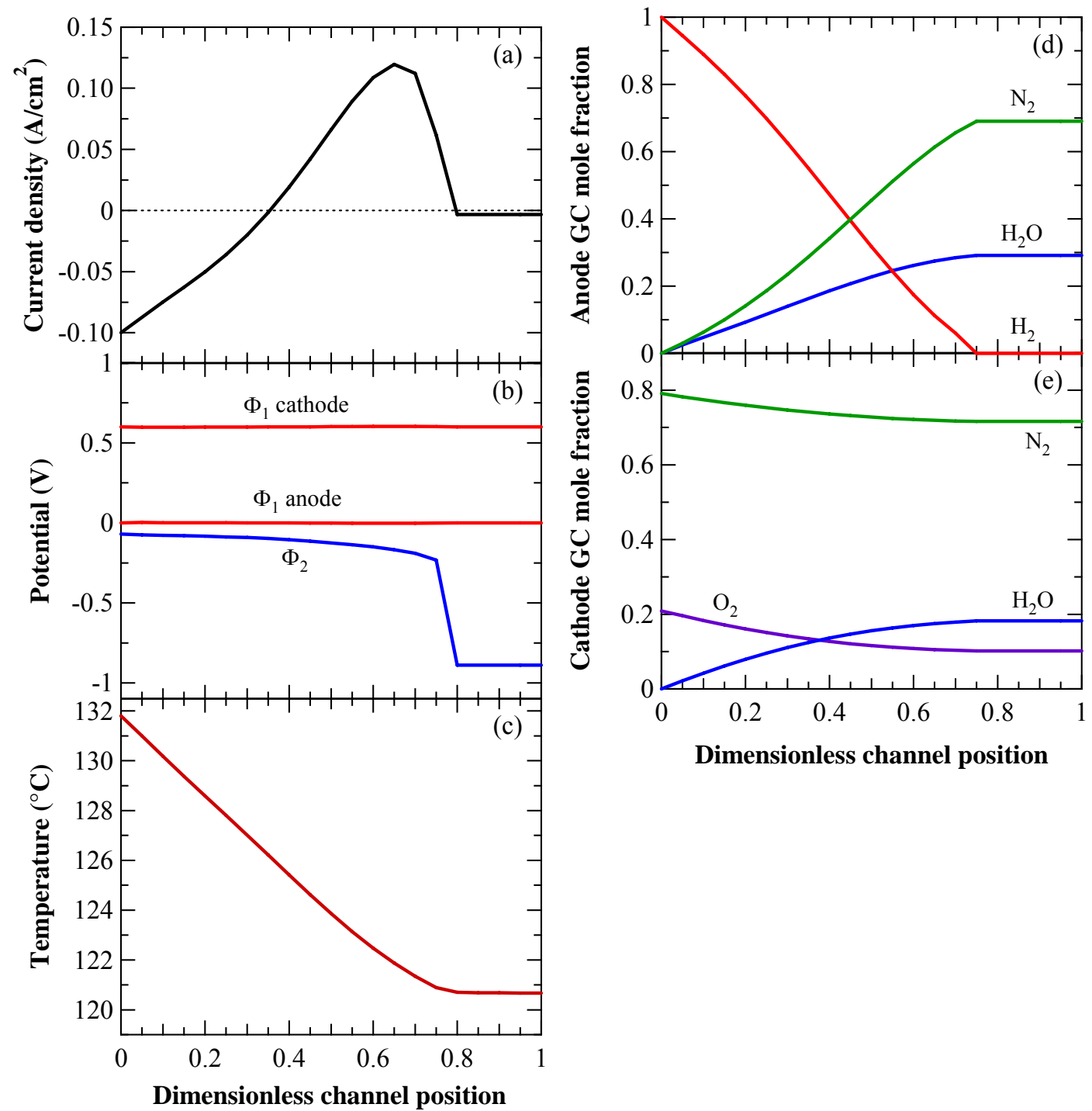

Figure 6. Along-the-channel values (inlet on left, outlet on right) for the (a) current density, (b) anode and cathode catalyst-layer average electronic and average ionic potentials, (c) average sandwich temperature, (d) nitrogen, water, and hydrogen mole fractions in the anode gas channel, and (d) nitrogen, water, and oxygen mole fractions in the cathode gas channel. The simulation is for a hydrogen permeation coefficient of $6 \times 10^{-8} \mathrm{~mol} / \mathrm{s}-\mathrm{bar}-\mathrm{cm}, 0.6 \mathrm{~V}, 120^{\circ} \mathrm{C}$, dry feeds, and a $0.1 \mathrm{~S} / \mathrm{cm}, 25 \mu \mathrm{m}$ membrane. 


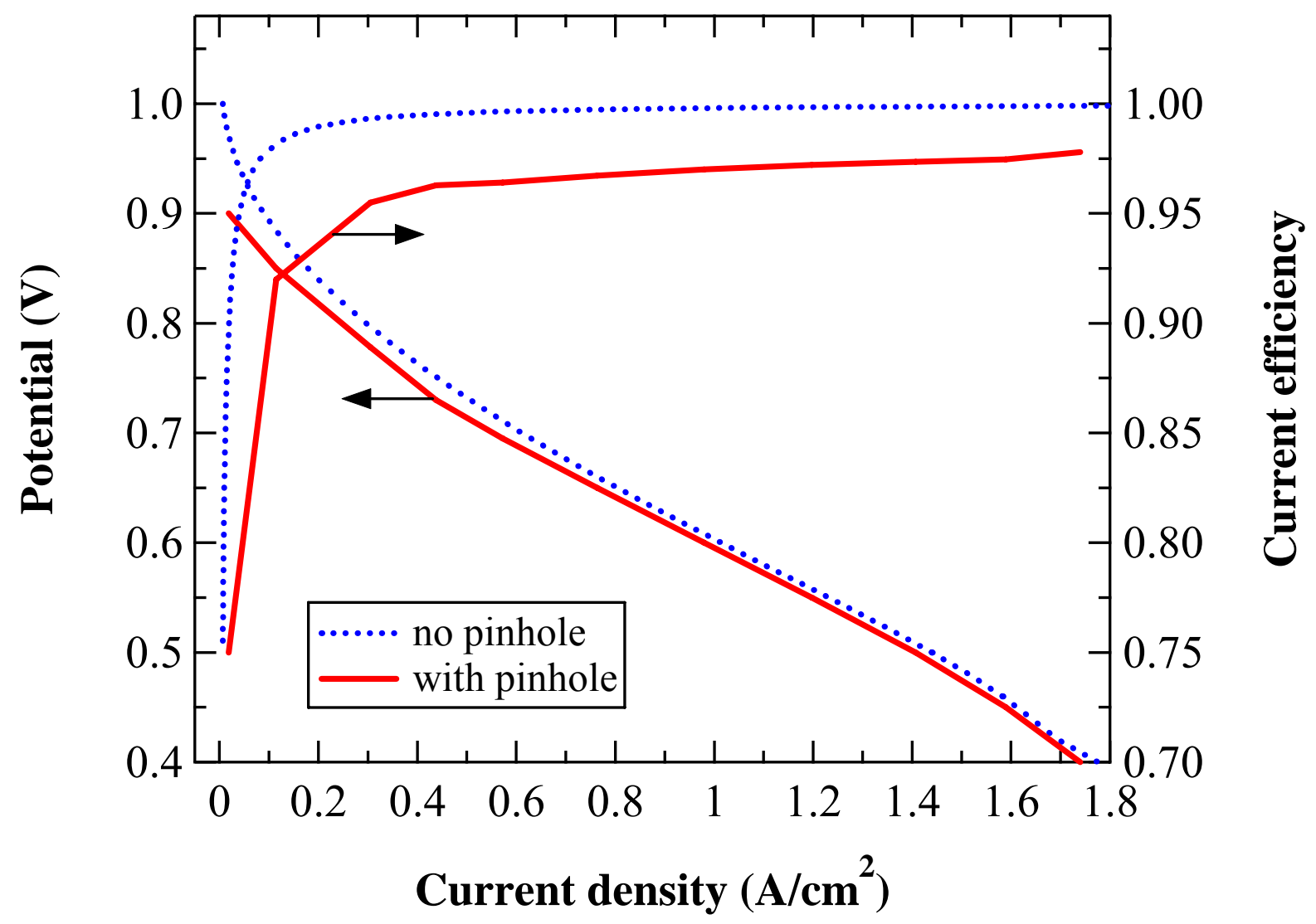

Figure 7. Polarization and current-efficiency curves for the case with and without a pinhole. The pinhole is in the middle of the cell and has a size of $0.08 \%$ of the active area. The simulation conditions are Nafion $112,65^{\circ} \mathrm{C}$, saturated inlets with utilizations of 83 and $50 \%$ for hydrogen and air, respectively. 


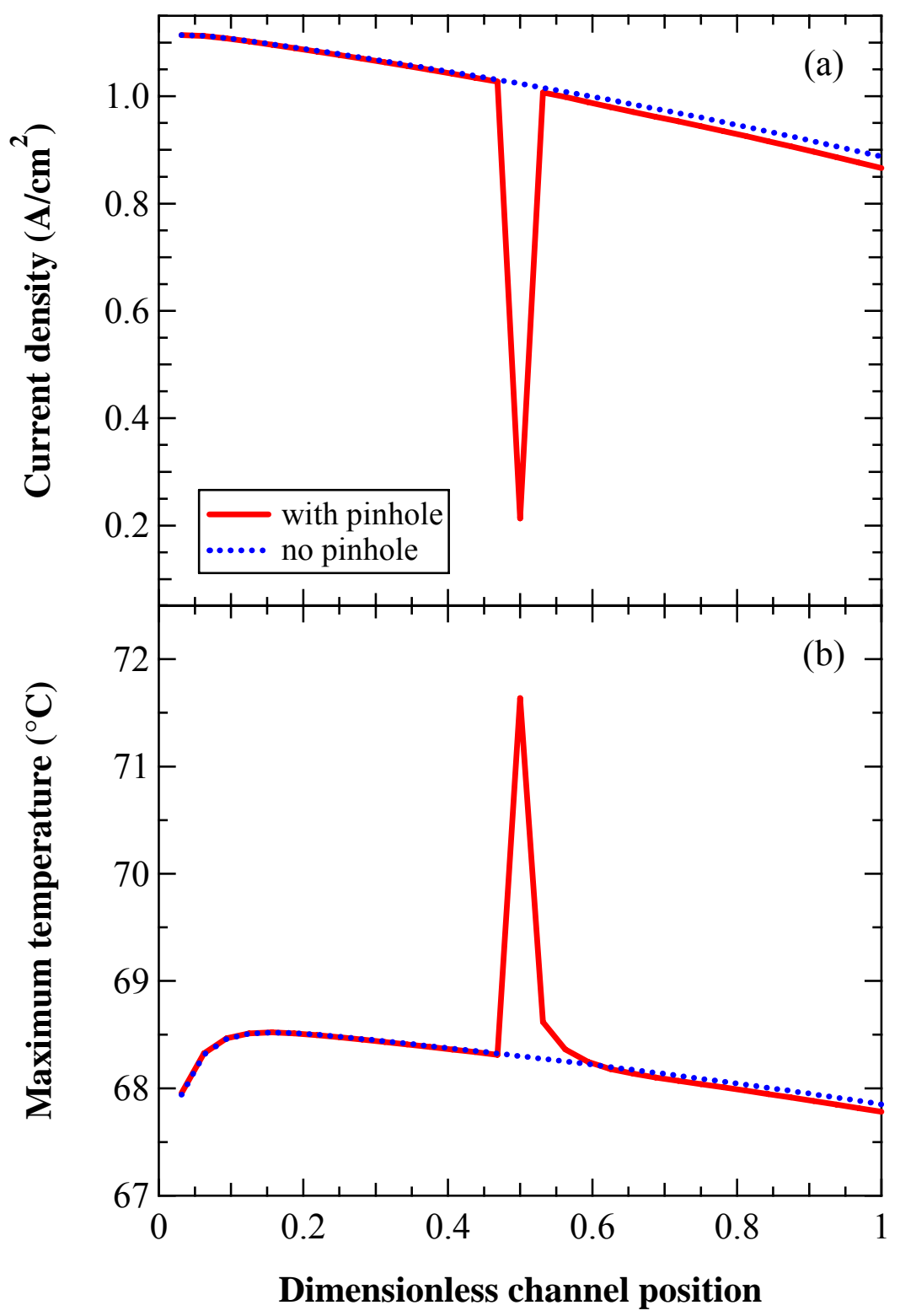

Figure 8. Along-the-channel values for the current density and maximum temperature (occurs in the cathode catalyst layer) with and without a pinhole. The conditions are the same as Figure 7 and the simulation is done at $0.6 \mathrm{~V}$. 


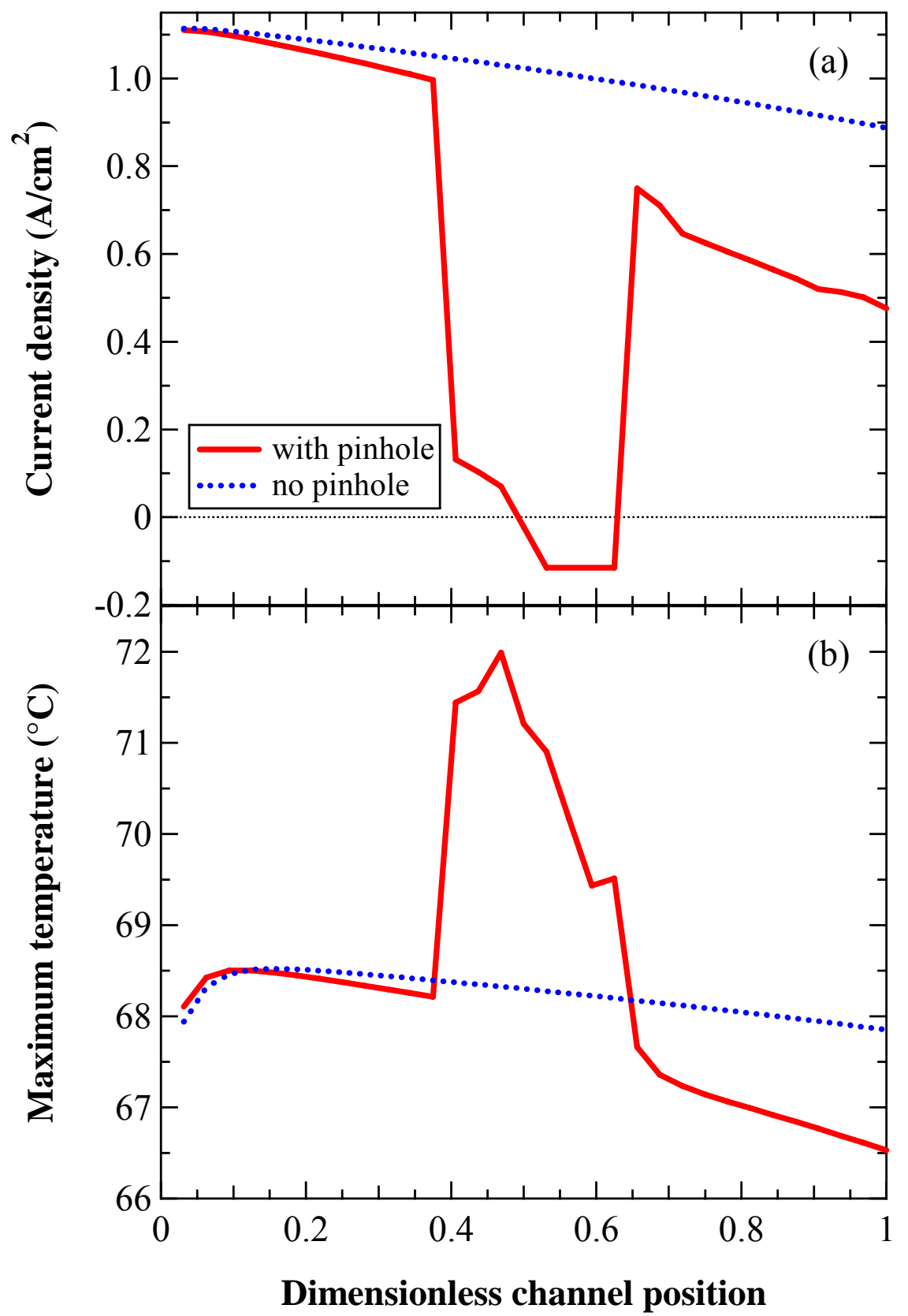

Figure 9. Along-the-channel values for the current density and maximum temperature (occurs in the cathode catalyst layer) for the cases without a pinhole and with 8 adjacent pinholes for a total area of $0.4 \%$ of the active area at $0.6 \mathrm{~V}$ (case 15 in Table $\mathrm{V}$ ). 